\title{
Contribution of Bayesian Networks to \\ Environmental Health Issues, Application to Etang de Berre
}

\section{Sandra PEREZ ( $\sim$ Sandra.PEREZ@univ-cotedazur.fr)}

University Côte d'Azur https://orcid.org/0000-0003-0562-0412

Catherine German Labaume

CIAS Martigues

\section{Sebastien Mathiot}

AtmoSud

Sylvaine Goix

Modelisation Conceptuelle des Connaissances Biomedicales

\section{Philippe Chamaret}

Institut ecocitoyen pour la connaissance des pollutions

\section{Research Article}

Keywords: petrochemical complex, etang de Berre, environmental health, Bayesian networks, artificial intelligence

Posted Date: August 3rd, 2021

DOl: https://doi.org/10.21203/rs.3.rs-776912/v1

License: (c) (1) This work is licensed under a Creative Commons Attribution 4.0 International License. Read Full License 


\title{
Contribution of bayesian networks to environmental health issues, application to Etang de Berre
}

\author{
Authors \\ Sandra Pérez corresponding author University Côte d'Azur, UMR 7300, Nice, France \\ Catherine German-Labaume, Head of the Health and Handicap Pays de Martigues Department, \\ Sébastien Mathiot, in charge of territorial action, AtmoSud \\ Sylvaine Goix, Head of health environment at the Institut Ecocitoyen pour la Connaissance des Pollutions \\ Philippe Chamaret, Director of the Institut Ecocitoyen pour la Connaissance des Pollutions
}

\begin{abstract}

\section{Background}

The aim of this study is to examine in detail the potential links between proven pathologies in the population and the atmospheric pollution to which this population is exposed, in an industrial context (Etang de Berre) and an abundant cocktail of pollutants, in connection with the diversity of emitting sources within that space (petrochemical industry, steel industry, refining, energy production, cement works, road, sea and air transport).
\end{abstract}

\section{Methods}

A total of 178 variables of various natures (health, environmental and socio-economic) on a fine territorial scale (infracommunal) have been mobilised and simultaneously integrated within a Bayesian model based on artificial intelligence. Various unsupervised and supervised algorithms, and also sensitivity analyses provide the means to discover the links between these variables and the inhabitants' living space.

\section{Results}

By mobilising a high number of variables, broken up on a fine territorial scale, and by resorting to an appropriate tool to report on existing links between these variables, we were able to bring to the fore a number of relations between exposure and proven pathologies. For example, between cadmium and diabetes in the over 65 year-olds, or between vanadium and respiratory diseases. Threshold effects have also been revealed, notably for $\mathrm{SO}_{2}$ which appears from a very low exposure threshold $\left(6 \mu \mathrm{g} / \mathrm{m}^{3}\right)$, therefore far below standard, which is set at $50 \mu \mathrm{g} / \mathrm{m}^{3}$. It is also the case with hydrofluoric acid (HF), the effect of which is already felt from the $0.0028 \mu \mathrm{g} / \mathrm{m}^{3}$ threshold. Also, exposure to cadmium in its particle phase, for an exposure between 0.214 and $0.250 \mu \mathrm{g} / \mathrm{m}^{3}$, disrupts insulin metabolism in the over 65 . Finally, as soon as Benzo[k]fluoranthene (particle phase) exceeds the $0.672 \mu \mathrm{g} / \mathrm{m}^{3}$ threshold, it results in a higher number of hospital stays for respiratory diseases in the 15-65 age group. A vulnerability differentiated according to age groups also appeared. Comorbidities known in literature have been found (respiratory and heart diseases). Also found was the influence of socio-economy on some pathologies (single-parent families and those without qualification at 15). Finally, diffuse PCBs pollution has been observed in the study area.

\section{Conclusion}

The study has brought forward differentiated health profiles between the various IRISes ${ }^{1}$ constituting the Pays de Martigues territory, and this should lead to the deployment of health services better suited to the needs of the population from a prevention perspective, and even to promote consultations with some specialists. For example, with a cardiologist, in those IRISes where the number of unqualified 15 year-olds is significant, since a relation has been found at that level, a relation most probably due to more difficult living and/or working conditions for these people. Likewise, prevention and social support measures should be taken to the benefit of single-parent families. At the same time, companies should go ahead with the desulfurization process of their installations, and even reduce their emissions concerning some noxious pollutants.

\footnotetext{
${ }^{1}$ Block groups of some 2,000 inhabitants forming the smallest statistical territorial division defined by the national institute of economic and statistical information INSEE
} 
Trial registration Decision DE-2017-413 authorising the Métropole d'Aix Marseille Provence to carry out the processing of personal health data for a retrospective and local environmental health study titled "Air-Health study in the Pays de Martigues territory." (Authorisation application No. 917120)

Key words petrochemical complex, etang de Berre, environmental health, Bayesian networks, artificial intelligence

\section{Background}

Open onto the Mediterranean, on the shores of the Etang de Berre, the Pays de Martigues constitutes a living area for close to 71,000 inhabitants spread over 3 communes: Martigues, Port-de-Bouc, Saint-Mître-les-Remparts. In addition to its geography, Martigues is Europe's leading petrochemical complex and therefore has a high concentration of polluting industries impacting the quality of air and the health of populations.

It was only from 2013 that a number of scientific studies began examining the health effects of air pollution at the Etang de Berre level. First came the REVELA study conducted by Santé Publique France between 2013 and 2016, focused on kidney and bladder cancers and acute myeloid leukaemia, that showed incidence rates for bladder cancers higher than those observed in mainland France [1]. Then, the FOS EPSEAL [2,3] study launched in 2015 and conducted in Fos-surMer and Port-Saint-Louis-du-Rhône attracted considerable attention because health data were collected on a random sample of inhabitants (participatory study), [4]. Nevertheless, the study revealed that chronic diseases and acute symptoms were a health experience shared in both cities. The prevalence in adults of cumulative asthma (starting most of the time in adulthood), of cancers (notably in women) and diabetes (notably type 1 diabetes) is higher in Fos-sur-Mer and Port-Saint-Louis-du-Rhône than in France on average. Respiratory ailments (hay fever excepted) concern almost one in two adults and one in four children. The INDEX [5] study conducted in 2016 at Fos-sur-Mer by the Institut Ecocitoyen pour la Connaissance des Populations (IECP) on blood and urine samples of a selection of 138 inhabitants revealed an over-impregnation of the population exposed by inhalation with lead, with two furans characteristic of industrial emissions and with benzene, but only in the oldest people. Gardening in an exposed zone was associated with a higher impregnation with total PCBs compared to the control zone. The fact of consuming vegetables from the garden was associated with a higher impregnation with cadmium in the exposed zone, whereas the effect was protector in the contact zone (Saint-Martin de Crau). Consuming local seafood (fish, shellfish) was associated with a higher level of impregnation with PCBs, dioxins/furans, mercury and chrome. Finally, the Scenarii and POLIS $[6,7]$ studies conducted in 2010 by AtmoSud in 66 communes around Etang de Berre and 39 substances led to calculating an excess health risk in a number of overexposed sectors.

This paper presents the results of a retrospective health geography study [8] of crossed data on pollution, impact of pollution on the environment (lichens), precariousness of residents and hospital stays by age group (i.e. 178 variables) carried out in the year 2015 in 3 communes of the Pays de Martigues, south of the Etang de Berre (Martigues, Port-deBouc and Saint-Mitre-les-Remparts) at the scale of the 30 Pays de Martigues IRISes, hence on a fine spatial scale.

\section{Methods}

\section{Materials}

\section{Health data}

They consist of 18 variables relating to pathologies of interest according to the 3 standard age groups (<15 years, 15-65 years, > 65 years), they relate to patients having stayed either at the Martigues Centre Hospitalier (CHM), or the Martigues Clinique privée, or in one of the 5 public hospitals ${ }^{2}$ or else at the Paoli Calmettes Institute (IPC), in 2015. Therefore, these data relate to numbers of hospital stays and not to numbers of patients. It was impossible in France to obtain "patient numbers" at the time when this study was carried out. The gender, in addition to the age segmentation, could not be retained because the "age" and "gender" association is too discriminatory and could lead to a potential identification of patients.

\footnotetext{
${ }^{2}$ Hôpital de la Timone (adults and children), Hôpital de la Conception, Hôpital Nord, and the 2 South hospitals (Sainte Marguerite and Salvator)
} 
The pathologies recognized in literature as being connected with this type of pollution $[9,10,11,12,13,14,15,16,17$, $18,19,20,21]$, are pathologies corresponding to the following ICD-10 3 codes:

. 100 to 1199 all diseases of the circulatory system in which are found for example ischemic heart diseases, coronary diseases,

. J00 to J199 all diseases of the respiratory system: laryngitis, pharyngitis, sinusitis, tracheitis, bronchopulmonary diseases, bronchitis, bronchiolitis, asthma, etc...

. E10 to E14 all diabetes types (type 1 insulin-dependent and type 2 non-insulin-dependent),

. C34 all types of bronchus and lung cancer,

. C67 for bladder cancer,

. C64 for kidney cancer,

The fact of dealing with a fine territorial scale imposes having enough cases per IRIS and consequently to work by batches of codes (for ex. 100 to 1199) rather than by separated codes.

\section{Air pollution data}

These health variables have been related to air pollution data provided by an approved air quality monitoring association in the Sud region (AtmoSud), a partner of this study, and also date back to 2015. In recent years, AtmoSud has developed an IT tool producing mappings of the annual levels of pollutants in the ambient air [6]. Thus we had measurements concerning 44 pollutants, half in gaseous form, and the other half in particle form; their levels were estimated both on models (air emission inventories + dispersion), and on measurements (long histories or one-off campaigns carried out in recent years) (Tables No $1 \& 2$ ). We had a choice between pollution measurements at the IRIS scale or at the scale of urban areas (built-up areas to the perimeter of which a $100 \mathrm{~m}$ buffer has been applied) (Figures No $1 \& 2$ ). We preferred the second option, which enables us to have a more accurate measurement of pollution in the population's living spaces (Map No 1), and this, all the more so since some IRISes are vast and their population sometimes gathered in a single area, as can be seen on map No 1 .

\footnotetext{
${ }^{3}$ International Classification of Diseases ICD-10 organised in 21 chapters, covering the full range of morbid conditions classified by organ or functional system: http://www.departement-information-medicale.com/wpcontent/uploads/2017/06/CIM10_2017_sts_20170009_0001_000.pdf
} 
Table No 1. Gaseous pollutants provided by AtmoSud

\begin{tabular}{|c|c|c|c|c|}
\hline & Pollutant & Formula & Model/measurement & Local background level $\left(\mu \mathrm{g} / \mathrm{m}^{3}\right)$ \\
\hline Gas & Sulphur dioxide & $\mathrm{SO} 2$ & $\mathrm{M}+\mathrm{m}^{*}$ & 0,6 \\
\hline Gas & Nitrogen dioxide & NO2 & $M+m^{*}$ & 8 \\
\hline Gas & Carbon monoxide & $\mathrm{CO} 2$ & $M+m$ & 263 \\
\hline Gas & Hydrochloric acid & $\mathrm{HCl}$ & M only* & $8,23 \mathrm{E}-04$ \\
\hline Gas & Hydrofluoric acid & $\mathrm{HF}$ & M onlyk & $5,29 \mathrm{E}-04$ \\
\hline Gas & Benzene & $\mathrm{C} 6 \mathrm{H} 6$ & $M+m$ & 0,7 \\
\hline Gas & Benzo[a]pyrene & BaP & M only* & $2,42 \mathrm{E}-06$ \\
\hline Gas & Polycyclic aromatic hydrocarbons & PAHs & M only* & 0,0021175 \\
\hline Gas & Dioxins and furans & $P C D D$ and $P C D F$ & M only" & $2,31125 \mathrm{E}-10$ \\
\hline Gas & Mercury & $\mathrm{Hg}$ & $\mathrm{M}+\mathrm{m}$ & $0,00106 \mathrm{ng} / \mathrm{m}^{3}$ \\
\hline Gas & Benzo[a]anthracene & $\mathrm{BaA}$ & M only* & $3,42 \mathrm{E}-06$ \\
\hline Gas & Benzo[b]fluoranthene & $\mathrm{BbF}$ & M only* & $2,68 \mathrm{E}-06$ \\
\hline Gas & Benzo[k]fluoranthene & BkF & M only* & $1,88 \mathrm{E}-06$ \\
\hline Gas & Indeno[1,2,3-c,d]pyrene & IcdP & M only* & $1,52 \mathrm{E}-06$ \\
\hline Gas & Dibenzo[a,h]anthracene & DahA & M only* & $3,124 \mathrm{E}-07$ \\
\hline Gas & Fluoranthene & Fluoran & M only* & $2,24075 \mathrm{E}-05$ \\
\hline Gas & Polychlorobiphenyls & $\mathrm{PCB}$ & M onlyk & $5,663 \mathrm{E}-07$ \\
\hline Gas & 1,3-butadiene & CAH6 & $M+m$ & 0,13 \\
\hline Gas & Hydrogen sulphide & $\mathrm{H} 2 \mathrm{~S}$ & M only* & $5,72 \mathrm{E}-06$ \\
\hline Gas & 1,2-dichloroethane & DCE & $M+m^{*}$ & 0,03 \\
\hline Particle & Under $10 \mu \mathrm{m}$ diameter particles & PM10 & $M+m$ & 16 \\
\hline Particle & Under $2.5 \mu \mathrm{m}$ diameter particles & PM2.5 & PM2.5/PM10 & 10 \\
\hline
\end{tabular}

Key: M: model, $\mathrm{m}$ : measurement, * the background is taken at the level of a point distant from any source (Etang de Rolland area). All data are expressed in $\mu \mathrm{g} / \mathrm{m}^{3}$ except for mercury (HG) expressed in $\mathrm{ng} / \mathrm{m}^{3}$

Table No 2. Pollutants in particle form provided by AtmoSud

\begin{tabular}{|l|l|l|l|}
\hline Pollutant & Formula & Model/measurement & Local background level $\left(\mu \mathrm{g} / \mathrm{m}^{3}\right)$ \\
\hline Benzo-a-pyrene & $\mathrm{BaP}$ & $\mathrm{M}+\mathrm{m}$ & $1,63 \mathrm{E}-04$ \\
\hline Polycyclic aromatic hydrocarbons & $\mathrm{PAHs}$ & $\mathrm{M}$ only & \\
\hline Dioxins and furans & $\mathrm{PCDD}$ and PCDF & $\mathrm{M}+\mathrm{m}$ & $1,38 \mathrm{E}-03$ \\
\hline Lead & $\mathrm{Pb}$ & $\mathrm{M}+\mathrm{m}$ & $2,16 \mathrm{E}-08$ \\
\hline Arsenic & $\mathrm{As}$ & $\mathrm{M}+\mathrm{m}$ & $4,02 \mathrm{E}-03$ \\
\hline Cadmium & $\mathrm{Cd}$ & $\mathrm{M}+\mathrm{m}$ & $3,86 \mathrm{E}-04$ \\
\hline Nickel & $\mathrm{Ni}$ & $\mathrm{M}$ only & $1,39 \mathrm{E}-04$ \\
\hline Mercury & $\mathrm{Hg}$ & $\mathrm{M}+\mathrm{m}$ & $2,03 \mathrm{E}-04$ \\
\hline Chromium & $\mathrm{Cr}$ & $\mathrm{M}+\mathrm{m}$ & $0,00 \mathrm{E}+00$ \\
\hline Chromium Vl & $\mathrm{Cr} \mathrm{Vl}$ & $\mathrm{Cr} \mathrm{Vl} /$ total Cr & $1,97 \mathrm{E}-03$ \\
\hline Copper & $\mathrm{Cu}$ & $\mathrm{M}+\mathrm{m}$ & $1,40 \mathrm{E}-04$ \\
\hline Selenium & $\mathrm{Se}$ & $\mathrm{M}+\mathrm{m}$ & $3,75 \mathrm{E}-03$ \\
\hline Vanadium & $\mathrm{V}$ & $\mathrm{M}+\mathrm{m}$ & $3,65 \mathrm{E}-04$ \\
\hline Zinc & $\mathrm{Zn}$ & $\mathrm{M}+\mathrm{m}$ & $2,51 \mathrm{E}-03$ \\
\hline Benzo[a]anthracene & $\mathrm{BaA}$ & $\mathrm{M}+\mathrm{m}$ & $1,93 \mathrm{E}-02$ \\
\hline Benzo[b]fluoranthene & $\mathrm{BbF}$ & $\mathrm{M}+\mathrm{m}$ & $1,38 \mathrm{E}-04$ \\
\hline Benzo[k]fluoranthene & $\mathrm{BkF}$ & $\mathrm{M}+\mathrm{m}$ & $3,09 \mathrm{E}-04$ \\
\hline Indeno[1,2,3-c,d]pyrene & $\mathrm{IcdP}$ & $\mathrm{M}+\mathrm{m}$ & $1,36 \mathrm{E}-04$ \\
\hline Dibenzo[a, $\mathrm{h}]$ anthracene & $\mathrm{DahA}$ & $\mathrm{M}+\mathrm{m}$ & $2,32 \mathrm{E}-04$ \\
\hline Fluoranthene & $\mathrm{Fluoran}$ & $\mathrm{M}$ only & $4,20 \mathrm{E}-05$ \\
\hline Polychlorobiphenyls & $\mathrm{PCB}$ & $\mathrm{M}$ only & $8,28 \mathrm{E}-06$ \\
\hline Diesel particles & $\mathrm{PM} 10$ diesel & diesel/PM10 & $6,30 \mathrm{E}-07$ \\
\hline & & $5,00 \mathrm{E}-01$ \\
\hline
\end{tabular}




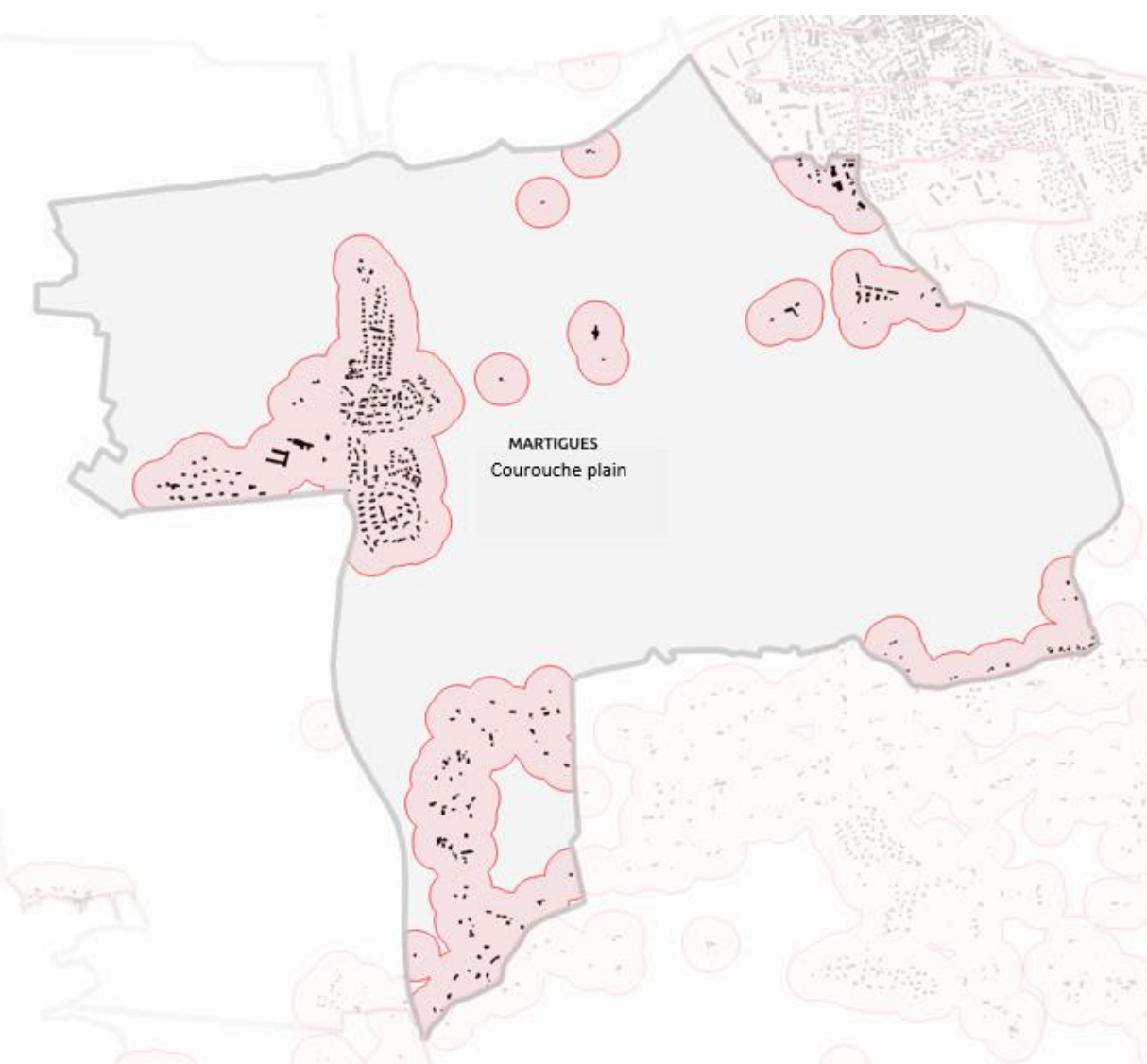

Figure No $1.100 \mathrm{~m}$ buffer applied on the perimeter of built-up areas, example with the IRIS of the Courouche plain in Martigues, Source AtmoSud

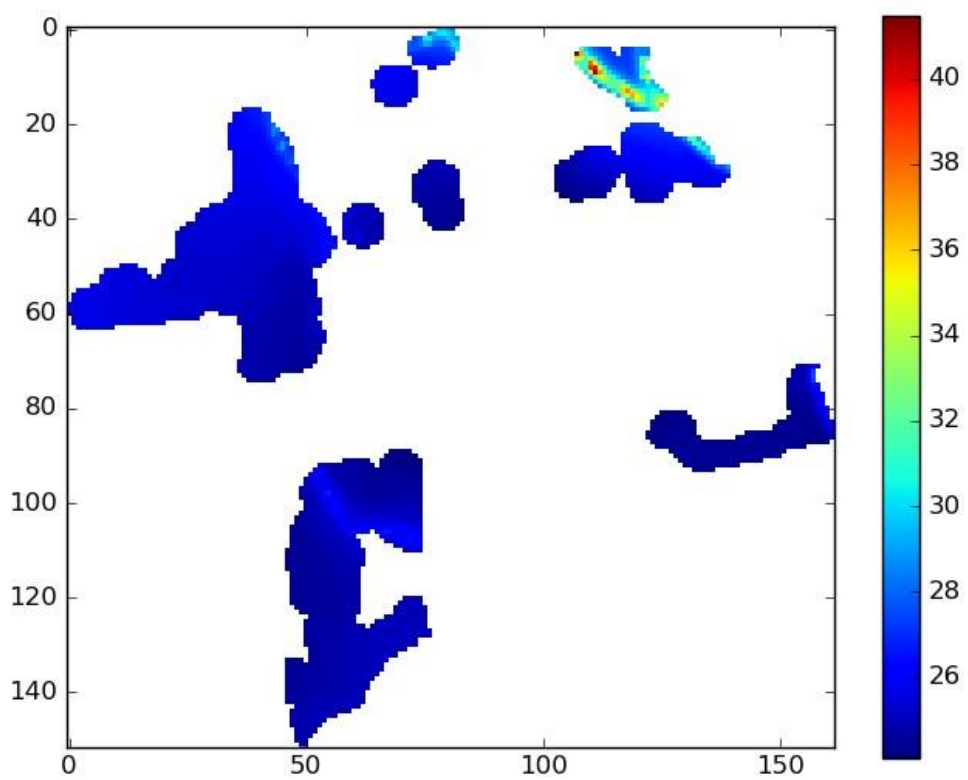

Figure No 2. Intersection of urban areas of the Courouche plain IRIS with air pollution data, Source AtmoSud 


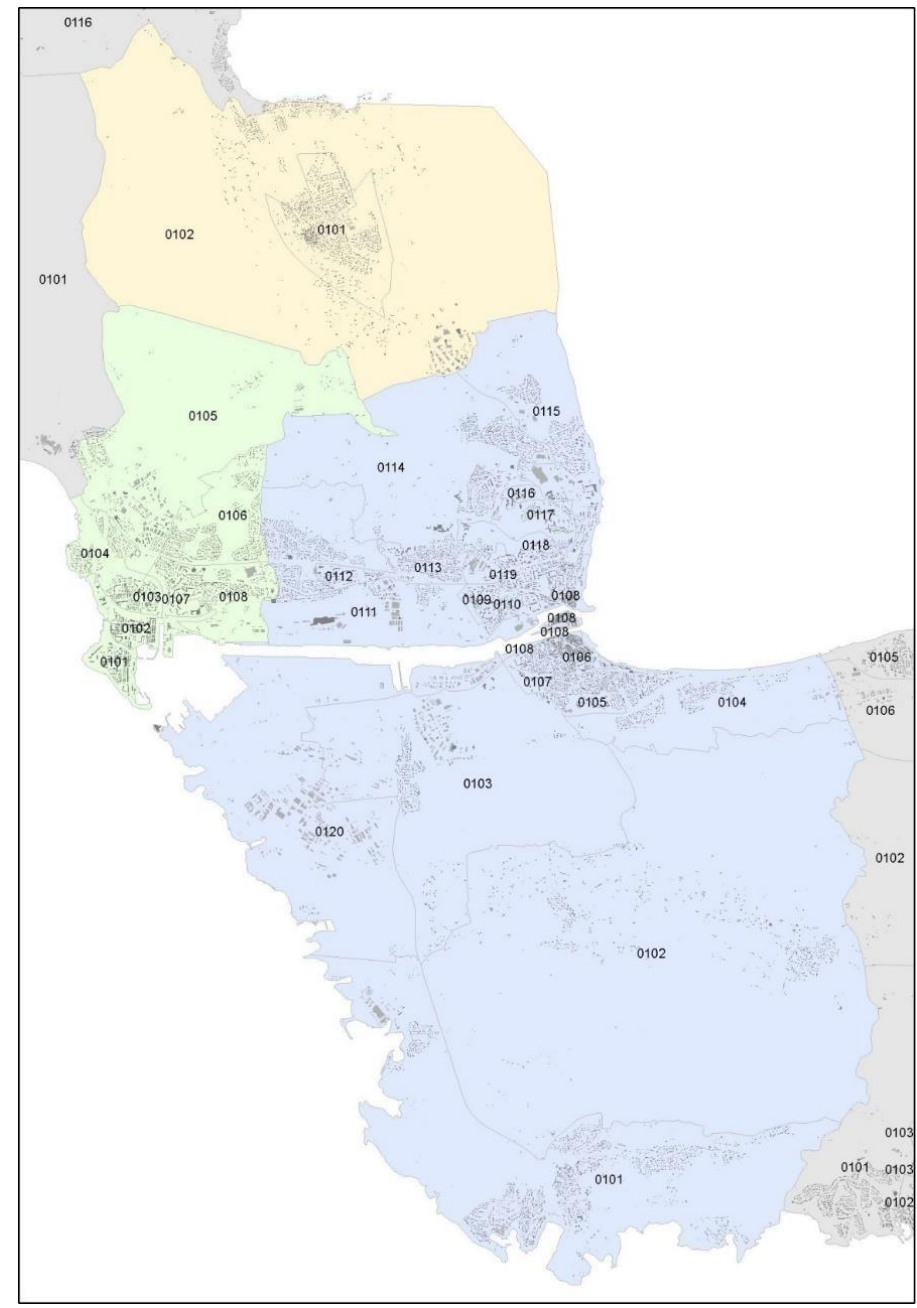

Map No 1. Urban areas in IRISes, Source AtmoSud

Lichen readings: bio-indication and bio-impregnation

Together with these 44 air pollution variables, we have 109 others corresponding to measurements carried out on lichen samples in September 2017, by the Institut EcoCitoyen pour la Connaissance des Pollutions (IECP) on specific plots (See Map No 2). These plots were selected in cooperation with the project's various stakeholders, and adapted according to the presence or absence of trees on location, where readings could effectively be carried out. In regard to the plots' spatial validity, a $500 \mathrm{~m}$ radius around the GPS point retained for the bio-impregnation plots can be considered. Indeed, according to a recent study carried out by the IECP [22], a variability of $35 \%$ maximum for metals, and $30 \%$ for the various congenerics of PAH has been measured in a plot within a $500 \mathrm{~m}$ radius. The impregnation results obtained represent a 6-month integration. These measurements on living organisms such as lichens are useful to limit a confounding factor that could be linked with the residents' way of life more than with the effects of air pollution (notably addiction to smoking); incidentally, most of them are located in IRISes known for being socio-economically disadvantaged. 


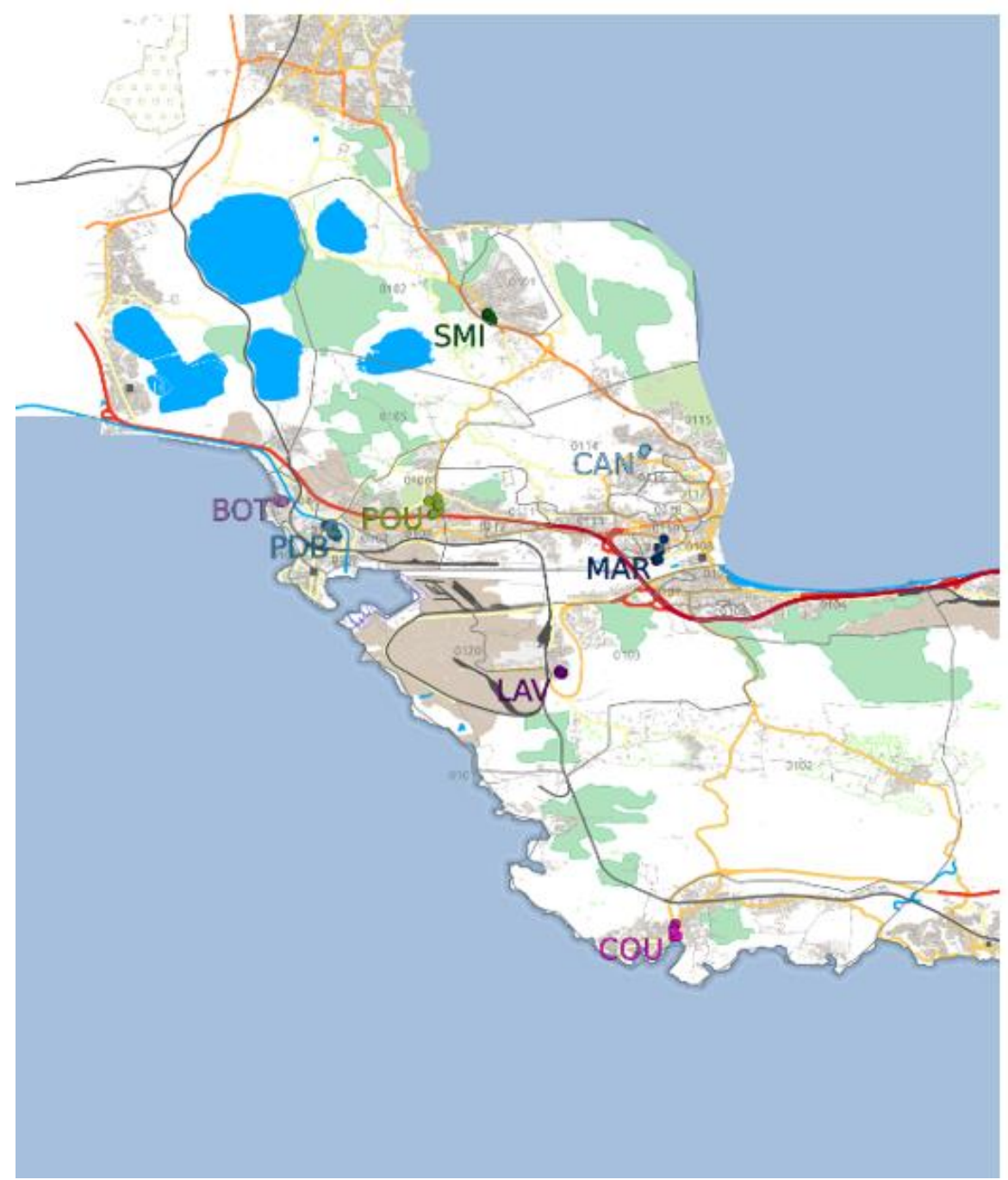

- BOT IRIS 0104 Port de Bouc

- CAU IRIS 0114 Martigues

- COU IRIS 0102 Martigues

- MAR IRIS 0108, 0110, 0119 Martigues

- PDB IRIS 0103 Port de Bouc

- POU IRIS 0106, 0111 Martigues

- SMI IRIS 0101 Saint Mître les Remparts

- LAV IRIS 0103 Martigues

Map No 2. Lichen sample plots, Source IECP

\section{Socio-economic data}

Finally, we have resorted to 7 socio-economic variables, because the effects of pollution will not affect everybody in the same way. The disadvantaged might be more exposed to them, but also might have less resources to counter them (postponing medical consultations by lack of means ${ }^{4}$, asthma and diabetes less well controlled). These variables come from the infra-communal databases of the National Institute of statistic and economic Studies (INSEE) in 2017, they concern:

. the number of people in 2017 in households living there for over 10 years, this variable being very useful to address the exposure of people P14_PMEN_ANEM10P

. the number of unschooled people of 15 or over and without qualification P14_NSCOL15P_DIPL0

. the number of people in households where the main family is a single-parent family C14_PMEN_MENFAMMONO

. the number of people in main homes occupied by tenants P14_NPER_RP_LOC

. the number of immigrants P14_POP_IMM ${ }^{5}$

. the number of unemployed in the 15 to 64 age group P14_CHOM15646

\footnotetext{
${ }^{4}$ Although it is forbidden, some doctors refuse beneficiaries of the universal medical coverage, this non explicit "refusal" is expressed by excessively long delays for obtaining an appointment, which may discourage some patients who may then decide either to postpone the consultation, or not to seek care, or else to go to emergency services for quicker attention, but to the detriment of follow-up.

${ }^{5}$ Variable subsequently related to the IRIS' total population for a more meaningful \%

${ }^{6}$ Variable subsequently related to the IRIS' 15 to 64 year-old working population for a more meaningful \%
} 
. median income DEC_MED14

These variables are useful to get to know the IRISes' level of precariousness or social disadvantage. We could have used a composite index, but we thought that it was important to keep these disaggregated variables, in order to see precisely on which variables differences between IRISes appear.

The whole of these variables (178) * 30 IRISes, corresponds to 5,340 cells in our database. These data are integrated within the same Bayesian model ${ }^{7}$, the probabilistic formalism of which is particularly suited to environmental health issues.

\section{The Bayesian networks}

Indeed, Bayesian networks allow to establish relations of dependence or independence among various variables, to analyse their interrelations, their combinations, by quantifying them using probabilities $[23,24,25,26,27,28]$. The context is that of a mathematical formalism of representation of uncertain knowledge, (probabilistic) particularly well suited to health risk issues, because relations between variables in health matters are not always determinist, but rather indirect. Moreover, Bayesian networks allow at the same time to model knowledge and produce new knowledge by revealing causal relations until now hidden (causal inference), or latent variables, and this, within the framework of unsupervised analysis (causal knowledge discovery). Very often, they bring added value in terms of knowledge, and constitute an interesting tool for the quantitative modelling of complex systems in uncertain fields, whether health or others. This is the reason why they are increasingly used worldwide, in fields as diverse as industry, finance, marketing, security and many others [29].

A Bayesian network is made up of two elements: a conceptual map and a database. The conceptual map defines the network's structure, it is a tool used for knowledge organisation and representation. This map is either built from data from the database, or from expert's knowledge of the subject studied. In our case, we decided to extract knowledge included in our database ${ }^{8}$.

The network's structure (or conceptual map) is visually represented by directed arcs representing the whole of the causal relations linking the variables, represented by nodes.

\footnotetext{
7 They are discretised as soon as they are integrated into the software, so as to be compared

${ }^{8}$ All processing was carried out using the specific software devoted to Bayesian networks: BayesiaLab 7.0.1
} 
The variables are then represented in node form:

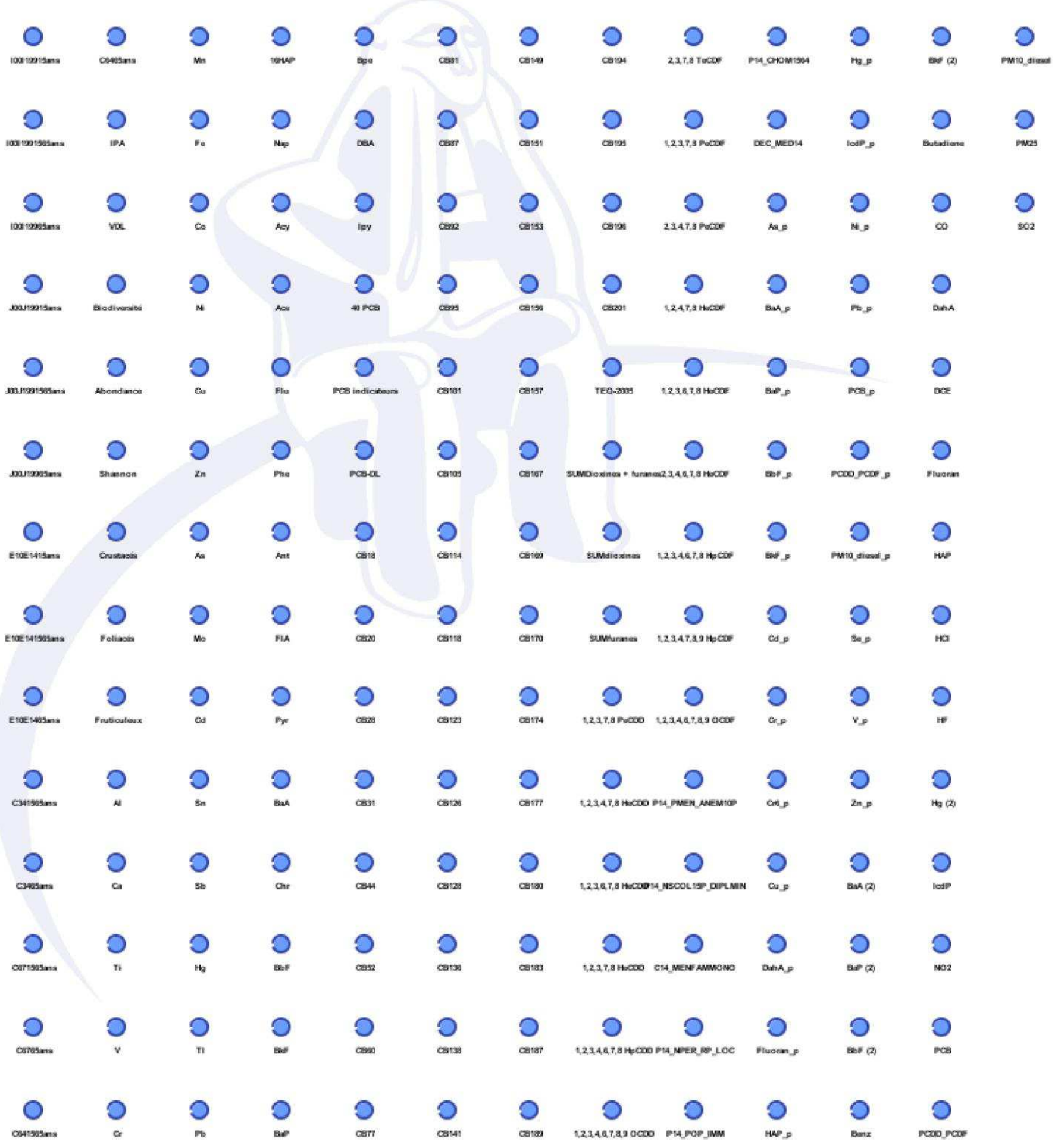

Figure No 3. The variables represented in node form

Between the nodes, causal links are drawn using an unsupervised artificial intelligence learning algorithm of the "maximum spanning tree" type, meaning that the algorithm will run until all the variables are connected with each other: 


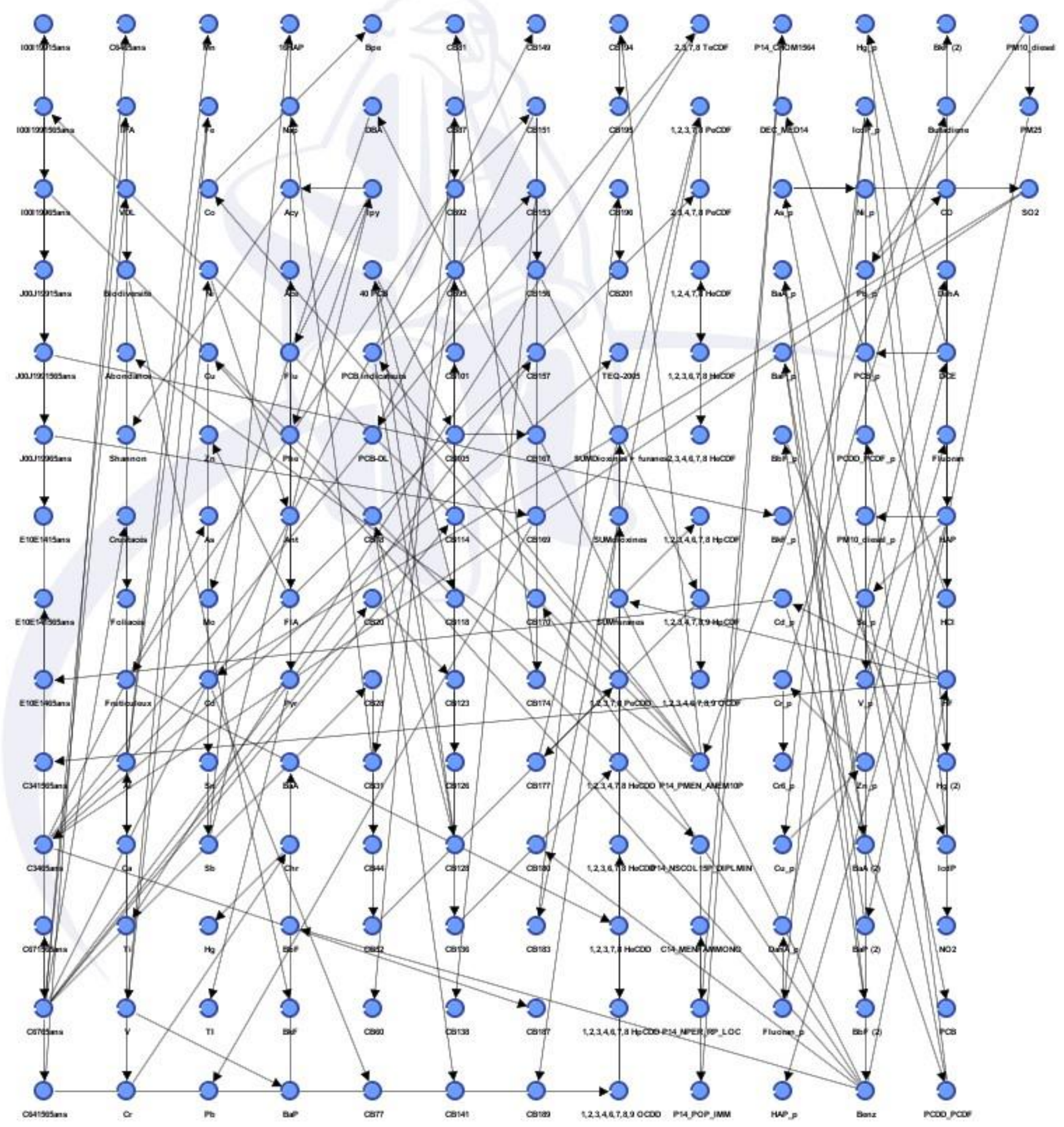

Figure No 4. The links between nodes

Thereafter, the conceptual map corresponding to our 178 variables appears in unsupervised form (Al), it represents the Bayesian network strictly speaking. (Figure No 5). In order to better distinguish the nature of the variables on the Bayesian network below, we have differentiated them by colours: orange for pathologies, green for variables resulting from lichen readings, purple for air pollutants, and blue for socio-economic variables. 


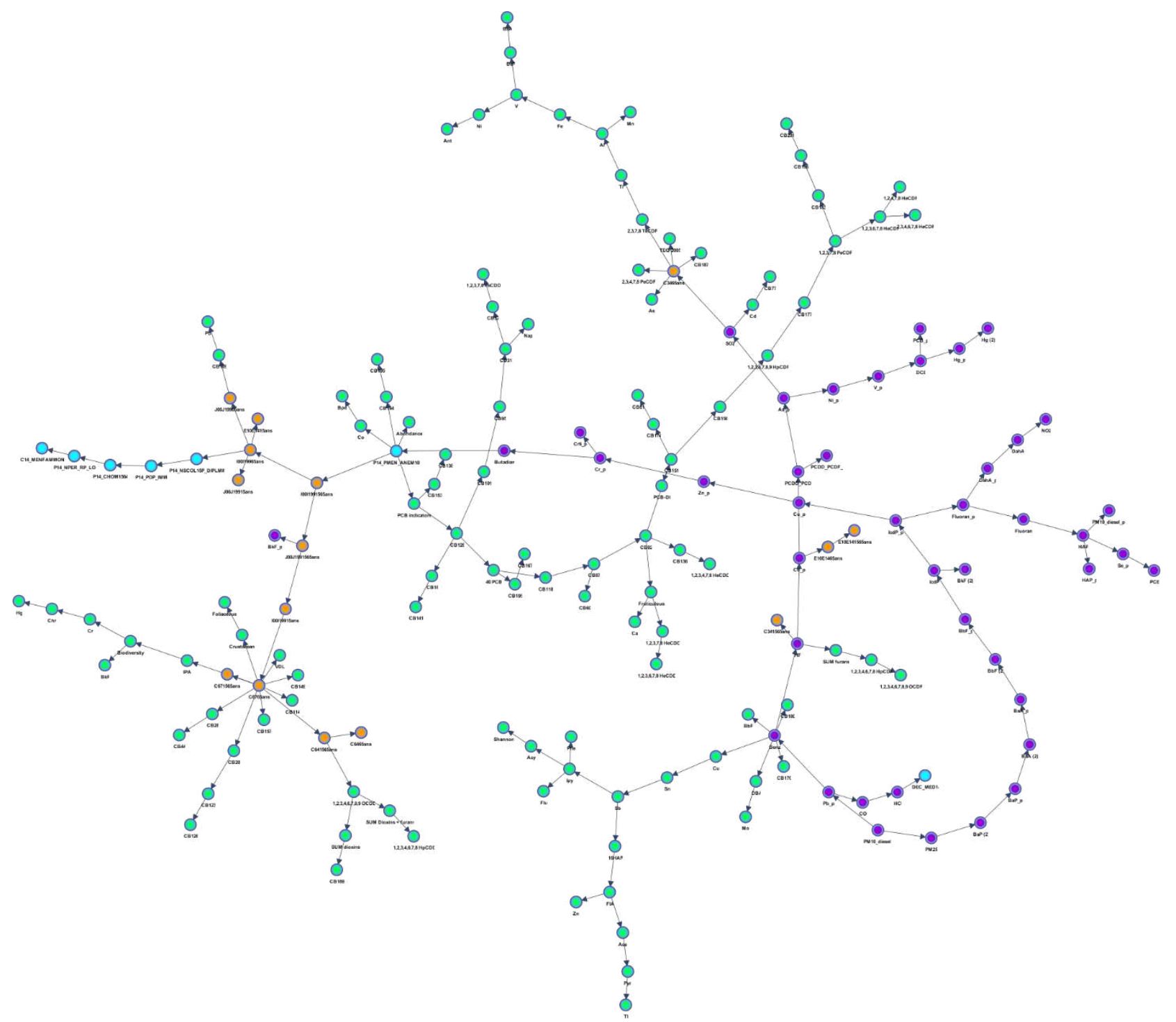

Figure No 5. The conceptual map of the 178 variables, the Bayesian network

Let's consider the health variables in orange, bearing in mind that they are the very object of this study ${ }^{9}$ and let's see with which other variables they are connected. The first concerns the number of households living in their IRIS for over 10 years (P14_PMEN_ANEM10P) and the relative abundance of lichen species ${ }^{10}$ (this relation is $70 \%$ positive). It could be interpreted as follows: the higher the relative abundance of lichen species is the more people tend to stay where they live (amenities). There is even a negative correlation between the relative abundance of lichen species and CB194 $(-0,70)$, however, a slight correlation (+0.6) links P14_PMEN_ANEM10P to Co (carbon monoxide), and cardiovascular diseases in the 15-65 year-old (I00I1991565ans, +0.65).

A second correlation can be observed in patients over 65 with cardiovascular (100119965ans) and respiratory diseases (J00J19965ans). It reveals a comorbidity which is well known by doctors [30], and already appears in younger patients

\footnotetext{
${ }^{9}$ We have underlined only significant correlations $(>0.65)$ except for those inferring a pathology which are systematically spotted ${ }^{10}$ The abundance relates to the sum of frequencies of each species on a plot. As the reading is done on 10 trees per plot, on all four faces of the tree and according to a 5-box observation grid, the frequency of each species on a spot is the ratio of the number of observations of the species on the plot divided by 200 ( 10 trees $* 4$ faces $* 5$ boxes). The abundance value is the sum of the frequencies of each species recorded on the plot
} 
(aged between 15 and 65: I00I1991565ans and J00J1991565ans), it is explained by the chronicity of these pathologies (I00I1991565ans - I00I19965ans, +0.67), as is the case with diabetes (E10E1465ans - E10E141565ans, +0.73).

We'll also note a rather strong relation $(+0.78)$ between respiratory diseases in the over 65 and a dioxin-like PCB recognized for its toxicity: CB169 ${ }^{11}$ [31].

An "interesting" link is observed (+0.63) between cardiovascular diseases in the over 65 (I00I19965ans) and a socioeconomic variable: no qualification P14_NSCOL15P_DIPLMIN, and also between income (DEC_MED14) and exposure to a $\mathrm{HCl}$ pollutant (Hydrochloric acid, negative relation of around 0.65 ) meaning that the more the households income increases the less they are exposed to that pollutant.

As regards bronchus and lung cancers in the over 65 (C3465ans), we observe a number of positive relations with pollutants, notably with CB187 (+0.80), TEQ-2005 12 (+0.83), 2,3,7,8 TeCDF (+0.86), 2,3,4,7,8 PeCDF (+0.84), As (+0.78) and $\mathrm{SO}_{2}(+0.62)$. Concerning bladder cancer, relations also appear in the over 65 (C6765ans) with VDL ${ }^{13}(+0.67), \mathrm{CB}^{20}$ $(+0.64)$, CB114 (+0.85) and to a lesser extent CB157 (+0.52), the latter 2 PCBs (114 et 157) being also dioxin-like PCBs ${ }^{14}$.

At this stage of the analysis, it is time to examine a little closer the relations that we have found between pathologies, pollutants and socio-economy. To do so, we are going to monitor these relations in order to observe how they interact among themselves. Indeed, the contribution of the Al is not limited to establishing very easily causal inferences between all variables considered simultaneously, and representing them in a highly didactic manner in a conceptual map.

We will take the 2 strongest relations concerning pathologies and a variable of a different nature (either environmental or socio-economic). Therefore, we are going to analyse the interactions between respiratory diseases in the over 65 and CB 169, and the interactions between diabetes patients over 65 and a heavy metal in its particle phase, cadmium (Cd_p).

\section{Interactions between variables: monitoring}

Interactions between respiratory diseases in the over 65 (J00J19965ans) \& CB169 $(R+0,78)$

We have previously seen in analysing the relations that respiratory pathologies in the over 65 are linked with CB169 and that the relation is overall $78 \%$ positive. But what happens, more precisely, at the level of the various classes (modalities) of these 2 variables, how do these variables interact between each other? To answer this question, we are going to monitor them. The relation is first spotted in the Bayesian network (a), then we monitor the variables (b), and we see what happens at the level of some of their modalities (c). The number of modalities corresponds to the number of classes requested (K-means 5 classes).

\footnotetext{
11 Toxicity factor (TEF) CB169: 0.03

12 TEQ 2005 corresponds to the sum of PCBs and dioxins/furans expressed in toxic equivalents. The toxic equivalent of each congeneric is expressed by multiplying its concentration by its toxicity factor (TEF), which allows to weight the concentration of each congeneric by its "toxic efficiency". The TEFs used are those defined by the World Health Organisation (WHO) in 2005 (Van den Berg, 2006)

13 The Value of lichen diversity (standard EN 16413)

14 Toxicity factor (TEF) PCB 114 \& PCB 157: 0.00003
} 
a)

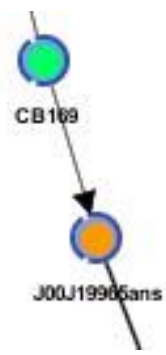

b)

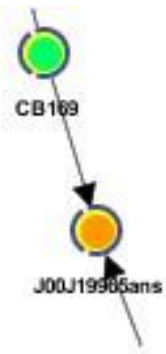

c)

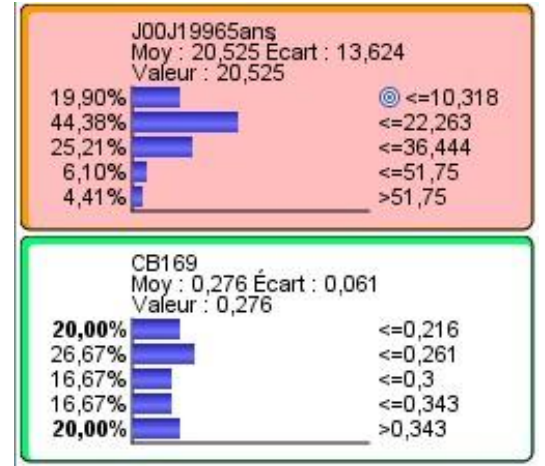

Figure No 6. Monitoring between J00J19965ans \& CB169

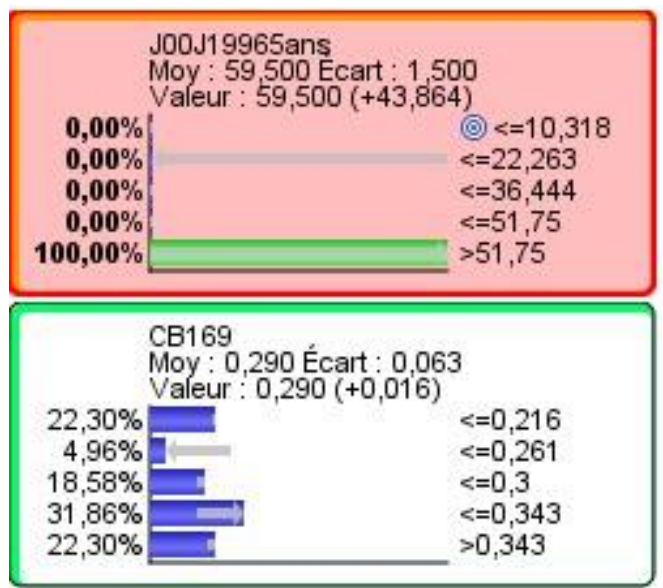

d.1) Highest J00J19965ans modality

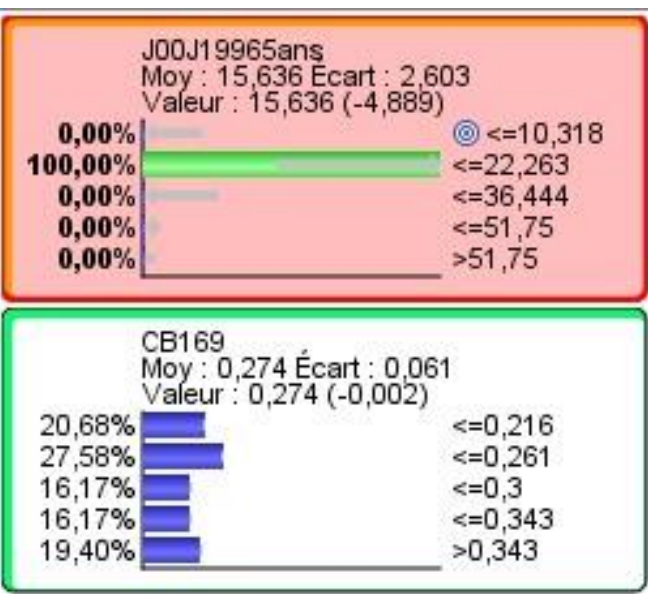

d.2) Most frequent J00J19965ans modality

What is particularly interesting now is to force one of these classes, for example the modality corresponding to the highest number of stays (here: number of stays $>51.75$ ), which then becomes green, and to observe how the associated probabilities of CB169 are then instantly updated. Thus, we can observe that if we focus on the highest numbers of stays, the values of CB169 increase, mainly for the 2 last modalities (for example evolution from 16.67 in the initial monitoring to 31.86 in d.1). Which means that when we consider the highest numbers of hospital stays recorded for respiratory pathologies in the over 65 in this territory, it is in relation with the highest values of CB169 found in the lichen readings $\mathrm{s}^{15}$. The most frequent modality $(44.38 \%)$ has also been forced without showing in that case notable changes in the monitoring.

Interactions between diabetes in the over 65 (E10E1465) \& Cd_p R +0.52)

A relation has appeared between diabetes in the over 65 and cadmium in its particle phase. Cadmium is absorbed in food (via deposits, air/soil pollution transfer) and could disturb insulin metabolism in the pancreas [32, 33]. This relation is very strong for the highest modality of diabetes patients (> 45.1 number of stays) and concerns a value of Cd_p between 0.214 and $0.250 \mu \mathrm{g} / \mathrm{m}^{3}$. For the most frequent modality, the relation already appears with the lowest values of Cd_p (38.18\% under or equal to $\left.0.181 \mu \mathrm{g} / \mathrm{m}^{3}\right)$.

\footnotetext{
${ }^{15}$ However, we should be careful in our interpretations, because the lichen readings are not exhaustive in the entire territory of study (for lack of time and means), nonetheless, the plots where readings were done reflect the impact of the environment in certain spots that have not been chosen at random, therefore the relations observed deserve wider investigation at a later date (more plots)
} 


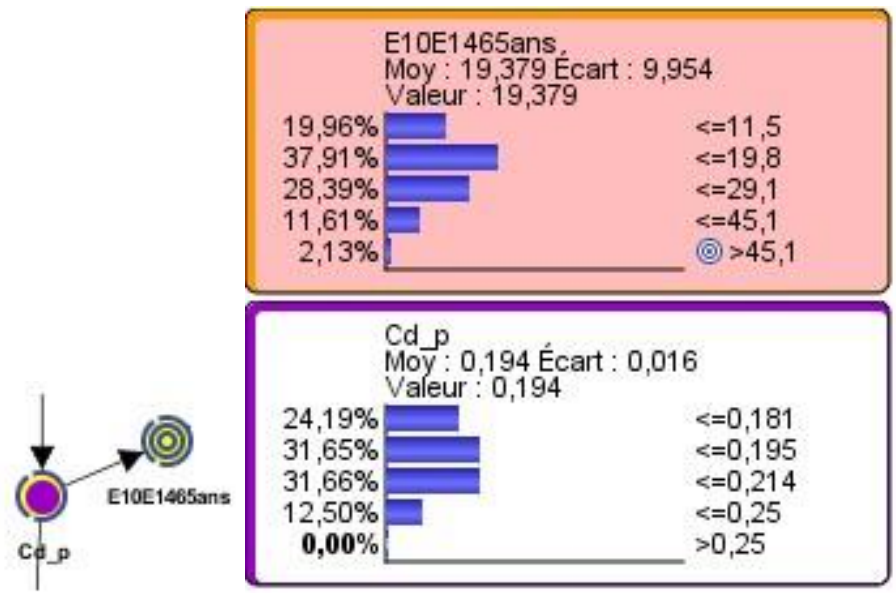

Figure No 7. Monitoring between E10E1465ans and Cd_p

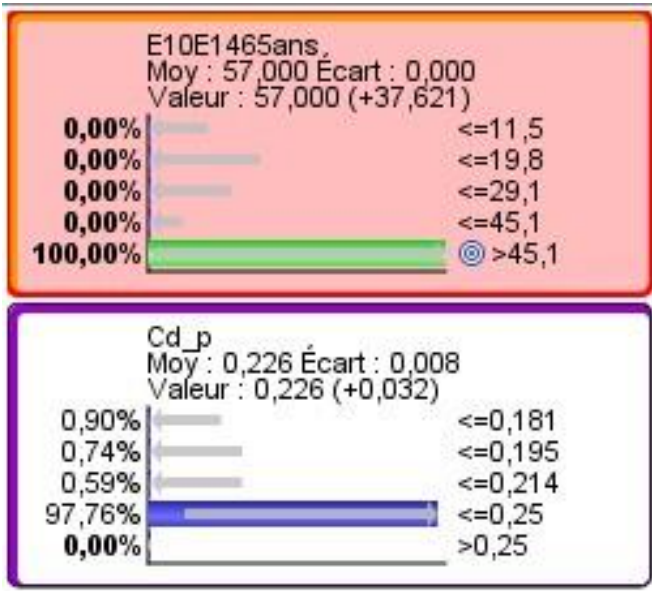

. Highest E10E1465ans modality

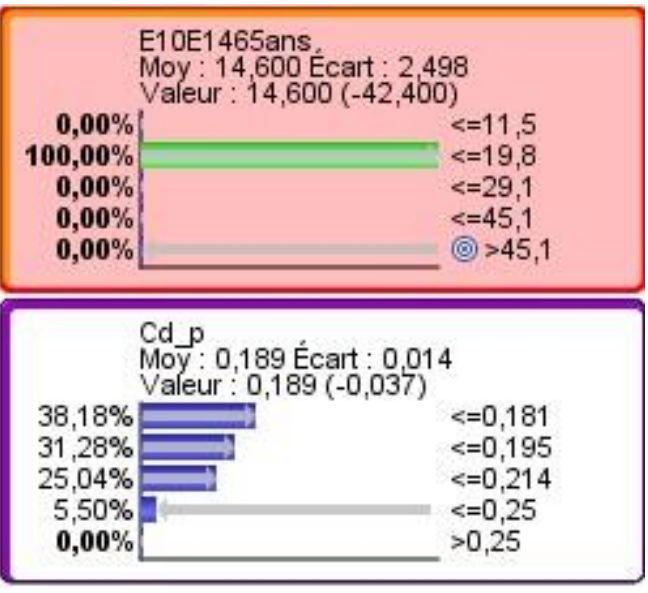

. Most frequent E10E1465ans modality

So far the analyses were global, on the whole of IRISes in the Pays de Martigues territory. It is now time to move to a finer scale and see how these relations vary according to IRISes, and whether some are more exposed than others. This will be achieved via a new process that will produce sensitivity analyses for each of the 30 IRISes included in our area of study (the design of the study, Figure 8 below). 


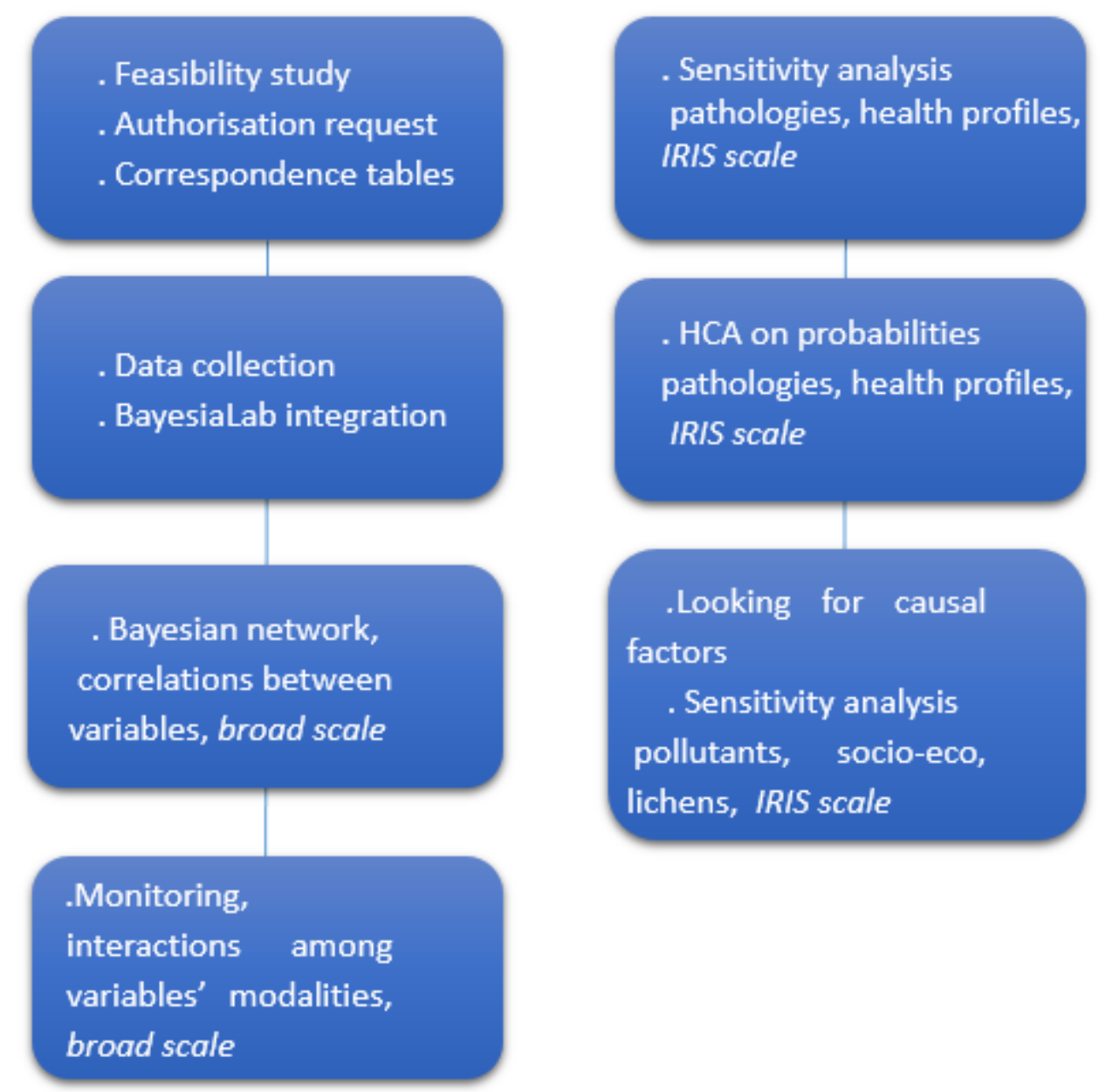

Figure No 8. The design of the study

\section{Sensitivity analyses per IRIS}

From now on, the IRIS variable will become the most important variable, it becomes a target variable. Below is the result of the supervised processing algorithm of the "augmented naïve" type run on the IRIS target variable, for pathologies. 


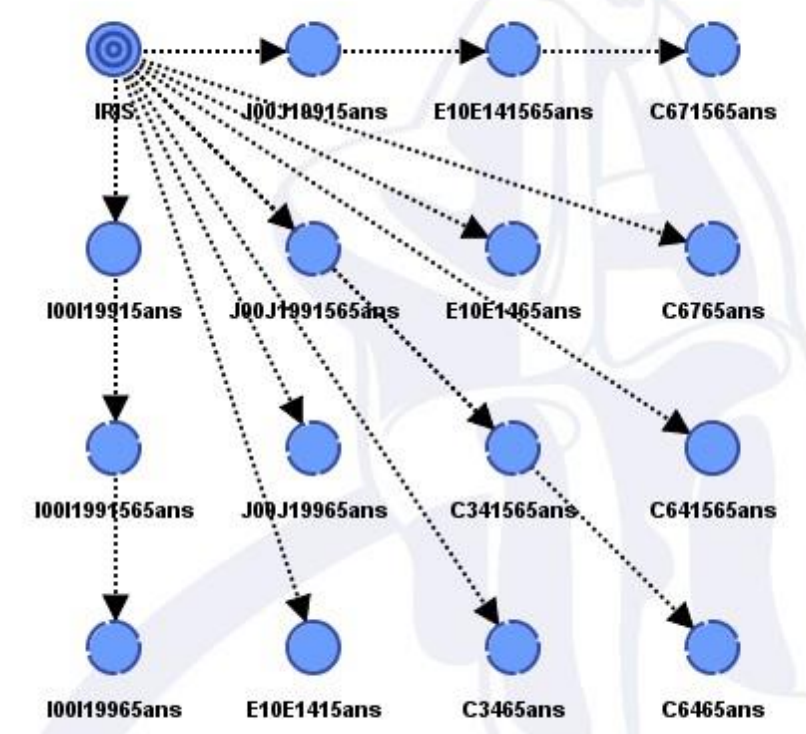

Figure No 9. Supervised processing on the IRIS target variable for pathologies

Sensitivity analyses are established starting from that algorithm. The figure below represents all sensitivity analyses per pathology, it enables us to observe the heterogeneity of IRISes between each other.

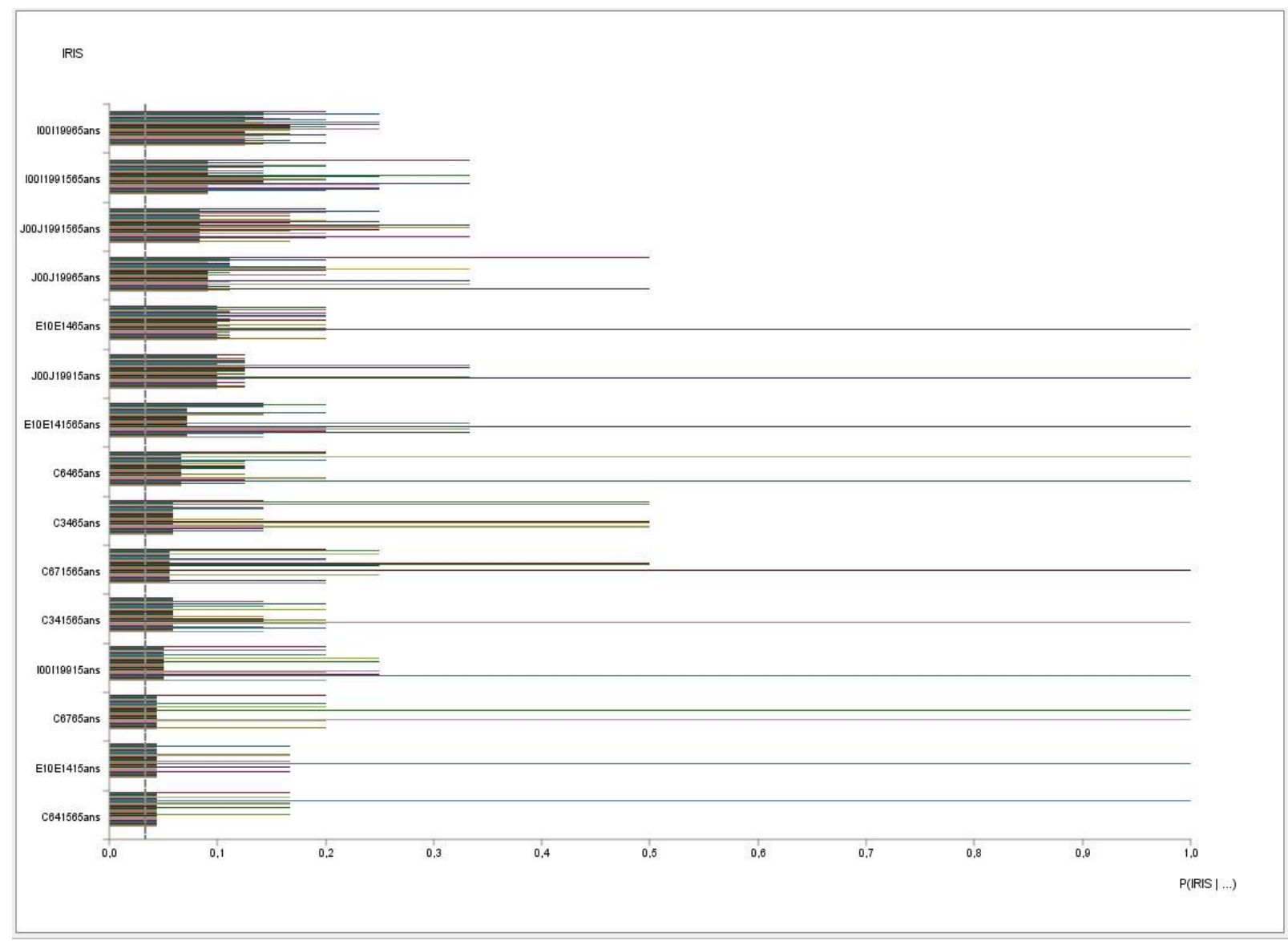

Figure No 10. All sensitivity analyses per pathology for all IRISes 
As an example, below is the sensitivity analysis on pathologies, carried out on IRIS 130560101 (Côte Bleue), in Martigues, which shows that respiratory diseases in the over 65 have a high probability to be found in that IRIS - approximately $50 \%$ - followed by cardiovascular diseases in the $15-65$ for $35 \%$, and so on.

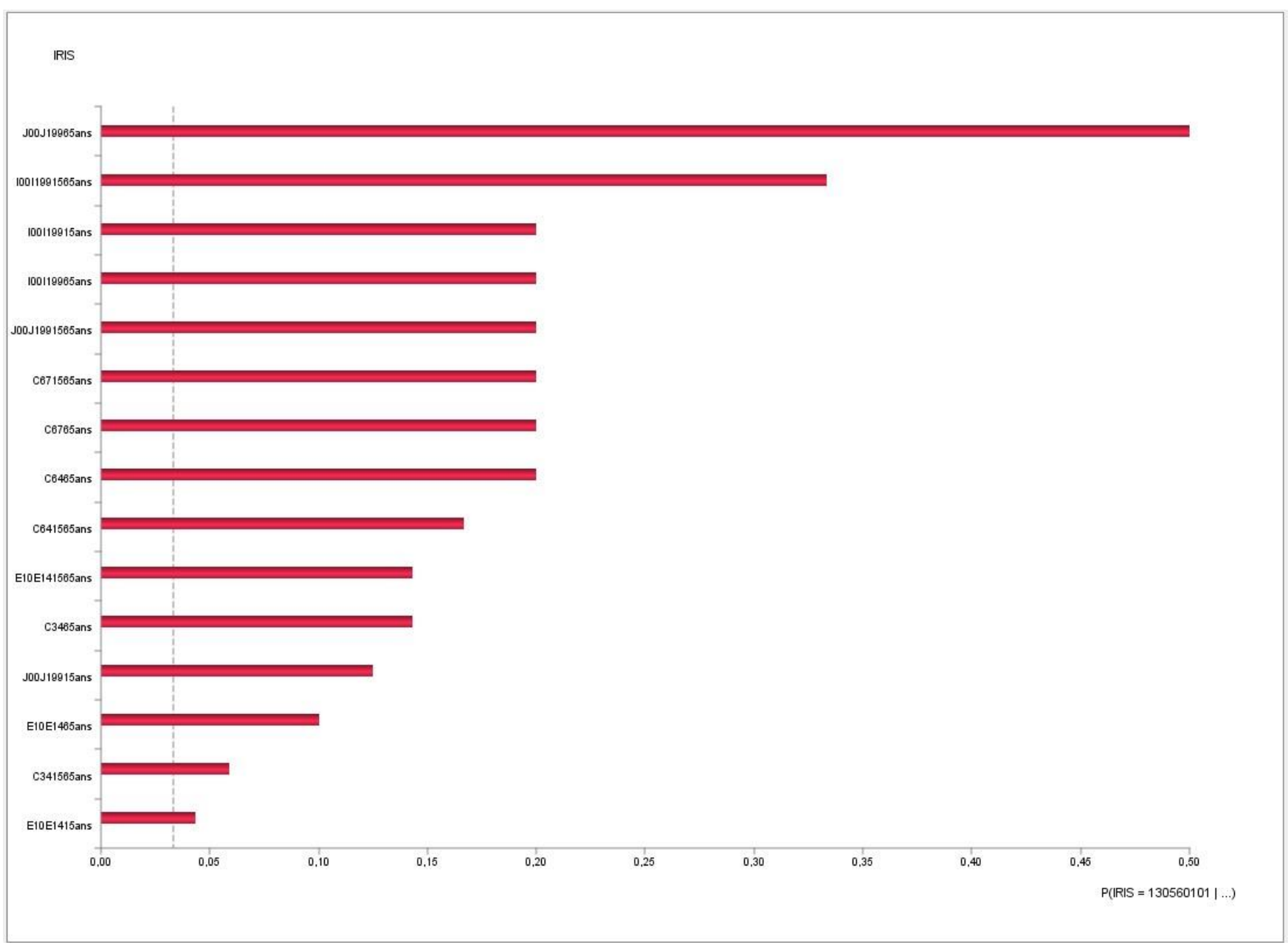

Figure No 11. Sensitivity/pathologies analysis for the Côte Bleue IRIS (13560101) in Martigues

Subsequently, we have taken the probability values ${ }^{16}$ for each IRIS and solely in regard to pathologies, then these probability values have been divided by the $\%$ of individuals in each age group so as to contextualise them and eliminate possible size effects, in case the number of elderly people would be proportionally higher in one IRIS than in others. Therefore, a high value indicates a high number of stays for the pathology and the IRIS in question, and so independently from the \% of elderly people in that IRIS. These values are subsequently integrated within an Ascending Hierarchical Clustering (below) so as to form groups of IRISes with a similar health profile. In total, 5 groups of IRISes can be clearly distinguished.

${ }^{16}$ For example, concerning IRIS (130560101) on figure No 10, the probability for respiratory diseases in the over 65 is 0.5 


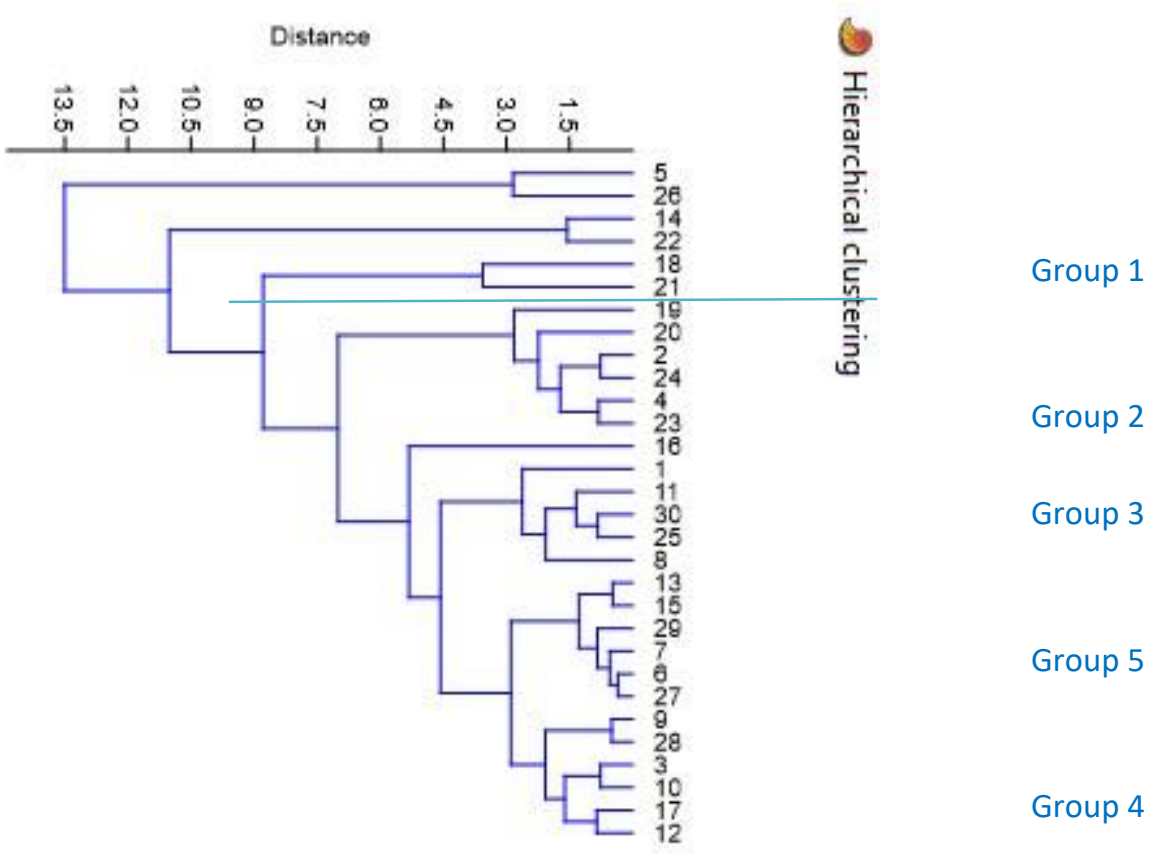

Figure No 12: Health profiles of the 30 IRISes established via HCA

Health profiles of the IRISes

- Group No 1 includes atypical IRISes as regards their health profile; it is clearly distinguishable from the other groups, since we find here the highest rates, for all pathologies on the whole.

. The second group differs from the others by less cardiovascular, respiratory and diabetes pathologies, but a higher rate of lung cancers in the over 65 (C3465ans).

What sets group No 3 apart are the high rates of cardiovascular diseases in the under 15 and above all cardiovascular diseases in the over 65 (1,21 on average), i.e. more than in the first group (0.81). The same is true for respiratory diseases from the age of 15 with rates almost twice as high as those of group 1 (1.33 against 0.70 ). Diabetes in the under 15 also individualises these IRISes. Bronchus and lung cancers in the over 65, without reaching the values of the second group, are also noteworthy ( 0.62 on average), just like bladder cancers in the same age group, without nonetheless exceeding group 1 (0.64 on average).

- Group 4 is in a way the reverse of group 2, insofar as we can observe more cardiovascular pathologies in the over 65 (1.13 on average), respiratory pathologies in the over 65 and at the same time in the under 15, and a lower cancer rate. There is a dissociation in terms of pathologies: the fact that we observe certain pathologies doesn't mean that there will be a higher rate of cancers (notably bronchus and lung cancer). This could be linked to the different nature of pollutants which therefore do not induce the same effects.

. Finally, the last group includes IRISes with pathology rates comparatively lower than in the other groups. It will be used as control group for our second verification of the model. Indeed, we may be tempted to take a control group "out-ofarea" which we estimate less exposed to pollution. Usually, a space in the "countryside" is selected. Now, the endocrine disruptors to which the population can be exposed via pesticides can induce the same pathologies (diabetes) [35, 36], which could confuse the "control cases" comparisons, since we might end up with high diabetes rates on both sides. 
Looking for causal factors

Then we went in search of the causal factors of health profiles, which can be either of an environmental nature, and/or of a socio-economic nature. The combination of both can form what we call pathogenic spaces [34]. Then sensitivity analyses have been carried out on each IRIS, taking simultaneously into account all air pollutants provided by AtmoSud (44 pollutants), all 17 variables resulting from the lichen readings previously detected as playing a part on pathologies ${ }^{17}$, and the 7 socio-economic variables, i.e. a new total of 68 variables (Figure No 12). Indeed, it might be interesting to distinguish those IRISes where environmental and/or socio-economic factors have an influence.

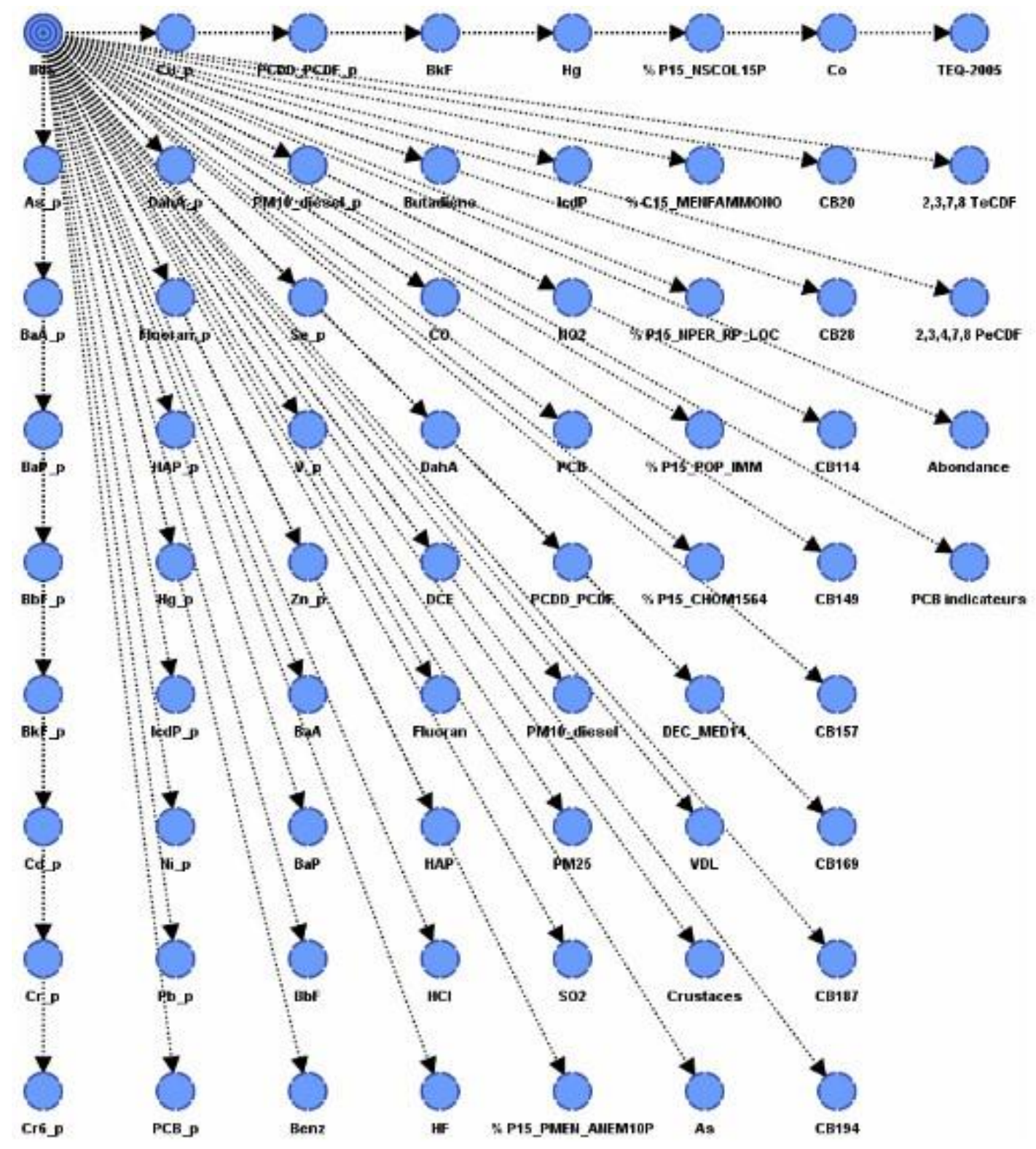

Figure No 13. Supervised processing on the IRIS target variable for pollutants, socio-economy and lichen readings.

Then, for each sensitivity analysis, we have taken the highest probabilized variables ${ }^{18}$.

${ }_{17}$ CB169, TEQ-2005, CB187, 2,3,4,7,8 PeCDF, As, 2,3,7,8 TeCDF, crustaceans, VDL, CB149, CB114, CB157, CB20, CB28, Co, CB194, Abundance, PCB indicators

${ }^{18}$ Without nonetheless exceeding the threshold of a 0.20 probability, except for example when a pollutant is known for having an impact (of the PCB type or others with a value of 0.18 ) 
We distinguished 3 main families of IRISes: IRISes where pollutants were many and formed what is commonly called a cocktail of pollutants $[37,38]$ which could contain either a majority of HAPs, or a majority of PCBs, or else pollutants that did belong neither to the HAP family, nor to the PCB family, and that we have therefore designated as "Others", but of which the potential impact on health deserves our attention nonetheless.

So, in total we have 3 IRIS profiles:

Cocktail of HAP pollutants (7 IRIS)

Cocktail of PCB pollutants (8 IRIS)

Cocktail of "Others" pollutants (15 IRIS)

We saw that to the first variable that comes out corresponds a probability value spotted in the sensitivity analyses; in a way, it indicates its level of importance in the IRIS. At times, this importance has been qualified depending on the other surrounding variables. Indeed, if we take the example of the Plaine de Courouche IRIS, the first variable that comes out in the sensitivity analysis is Butadiene with 0.31 , but we have preferred to retain CB20 which is just behind with 0.29 , because it is a potentially more impacting PCB for health. Likewise, we have indicated when it was pertinent the socioeconomic variable which came first and was integrated into the cocktail of pollutants in order to get an idea of the said context. Socio-economy, as we know, can add to the effect of pollutants and consequently have an impact but it can also in some cases offset this effect when it is favourable (better access to health care, better quality of life, better diet etc.).

HAPs group together several pollutants emitted at the same time, their number varies by a factor of two (6 to 12), with a repercussion on pathologies. The more HAPs, the more severe is the pathology. This is due to the carcinogenic nature of each of these $\mathrm{HAPs}^{19}$ (BaP, BaA, BbF, BkF, DahA, Fluoranthene, IcdP) and to their potential noxious mixing. The favourable socio-economy of the Jonquières Foulettes IRIS (130560107) seems to make up for the exposure of its residents (income above average), in the same way as for the Coudoulière IRIS (130560113), but to a lesser extent, because HAPs are less numerous in that IRIS.

Regarding the Cocktail of pollutants of the PCB type category, their health impact is essentially characterised, and even at low doses (due to their toxicity) by, for example, bladder cancers (IRIS Plan de Fossan - 130560114) in the over 65.

Finally, the last category, "Others", refers to pollutants that cannot be classified in the previous categories. It includes "traditional" pollutants such as $\mathrm{NO}_{2}$, or even $\mathrm{SO}_{2}$, but also hydrofluoric acid (HF), not forgetting other potentially impacting elements such as: V_p, Hg, Zn_p, Cd_p, Cu_p and the PCDD_PCDF.

Now let's consider the pathologies found in the IRISes and let's "correlate" them with the highest factors seen in these. The results are shown in the form of the maps below.

\footnotetext{
${ }^{19}$ https://www.atsdr.cdc.gov/csem/polycyclic-aromatic-hydrocarbons/health_effects.html
} 


\section{Results}

Group 1 of the HCA is exposed to particularly strong pollutants of the PCDD_PCDF type at La Lèque, CB28 ${ }^{20}$ at Plan Fossan, HF at PdB Centre and at St-Jean Bergerie, and to Dibenzo[a, h]anthracene (DahA_p) at Boudème. In 4 of the 6 IRISes, socio-economy (represented by white squares) combines with the pollutants and corresponds to single-parent families. In fact, it is the prevailing variable for the Rayettes IRIS $(0,31)$.

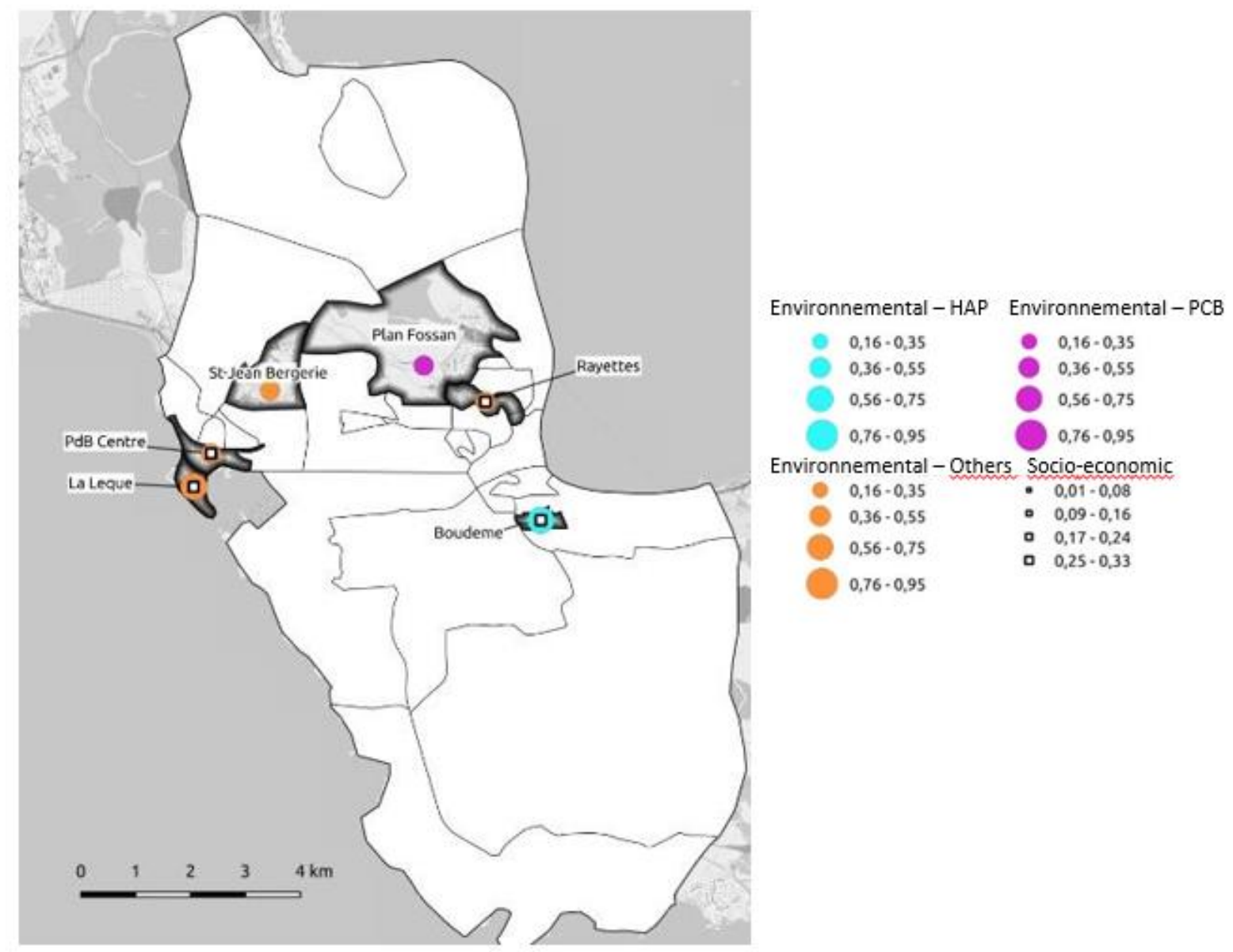

Profile of IRISes according to the probability of the prevalence of environmental and/or socio-economic factors Map No 3. Group 1 HCA; IRISes characterised by an increased prevalence of hospital stays for the whole of the pathologies studied

\footnotetext{
${ }^{20}$ When PCBs have been measured in lichens they are written in green, and in purple when they have been measured in the air.
} 
As for group 2 IRISes, they are exposed to PCBs (Tassy Est CB20, St-Pierre \& St-Julien PCB), to $\mathrm{SO}_{2}$ (Tassy Ouest), and to vanadium $[39,40]$ in its particle phase, and at much higher levels than in other IRISes for those of Lavéra and Côte Bleue. The Jonquières Est IRIS is exposed to over 11 different HAPs, the Notre Dame Paradis IRIS to $\mathrm{NO}_{2}$, but in the latter, like in Tassy Est, socio-economy also seems to play a pernicious part (unschooled at 15 and unemployment). The nature of pollutants (PCB, vanadium) and their multiplicity (11 different HAPs), could explain the pathologies found in the IRISes of this second HCA group.

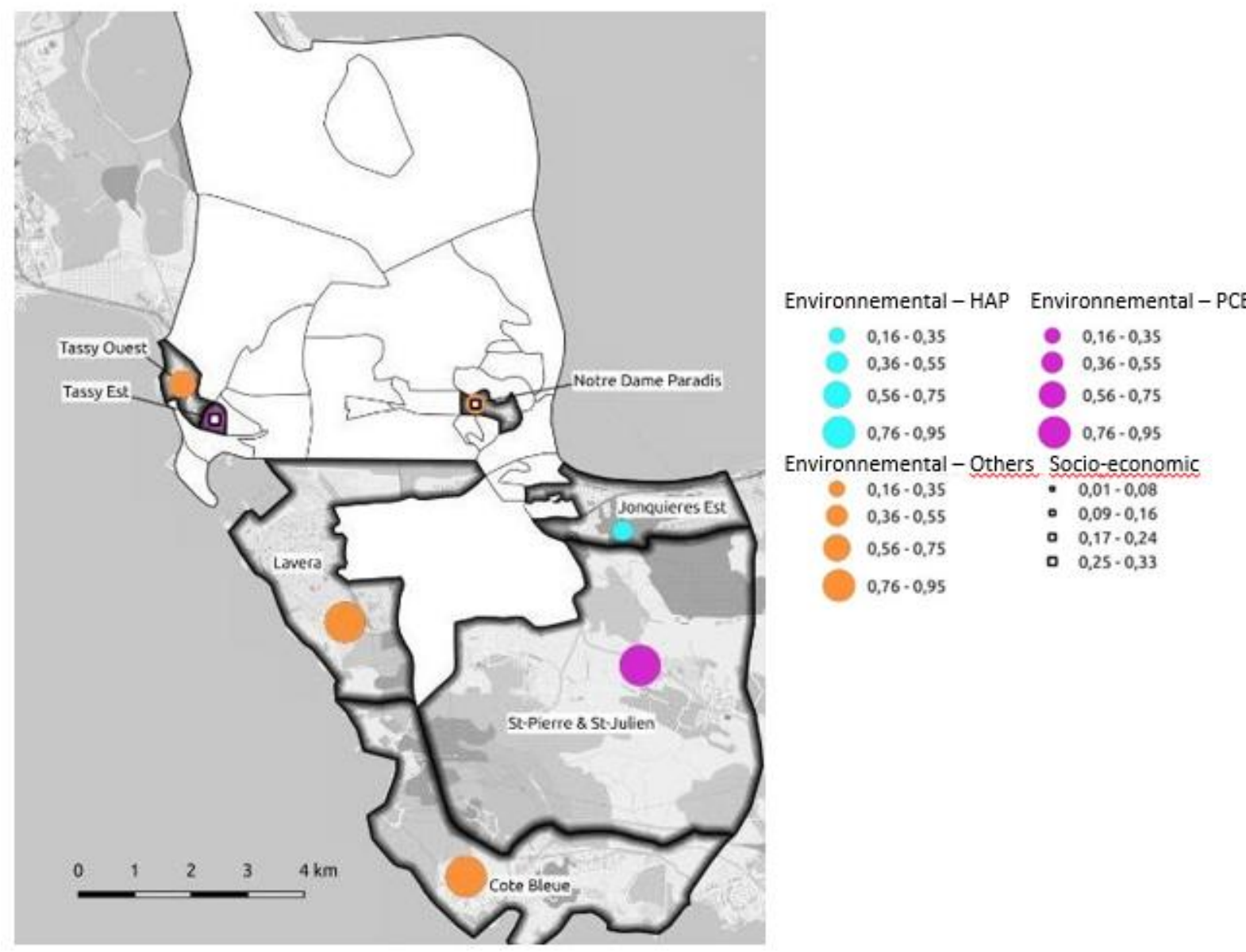

Profile of IRISes according to the probability of the prevalence of environmental and/or socio-economic factors Map No 4. Group 2 HCA, IRISes characterised by an increased prevalence of hospital stays related to lung cancers ( $>15$ ) and bladder cancers (15-65) 
Let's now have a look at the situation in group 3 IRISes. The Ferrière IRIS has a profile of the PCB type like the St-Mitre Périphérie IRIS; however, when one examines data for St-Mitre, the PCB values are not very high compared with other IRISes, but it is the first pollutant that comes out of the corresponding sensitivity analysis. In fact, this IRIS is simultaneously exposed to several pollutants ( $C o, Z n \_p, C r \_p, C r 6 \_p, P C D D \_P C D F, H C l, B k F \_p$ ), the value of each not being very high compared with other IRISes, except however from BkF_p which plays a part in respiratory diseases. As regards Gaps, $\mathrm{Hg}$ is the first pollutant that comes out, followed by $\mathrm{Co}, \mathrm{Cu}$ _p and HF, whereas Croix Sainte is rather characterised by the presence of $\mathrm{Zn} \_p$, followed by several pollutants of the PCB type, and As. Finally, variables of a socio-economic nature seem to have a greater impact on the Colline IRIS (immigrant population, single-parent families, unemployment and unschooled 15 year-olds, the latter variable having an impact on cardiovascular diseases), and Cd_p, that disrupts insulin metabolism, is the only pollutant in this IRIS.

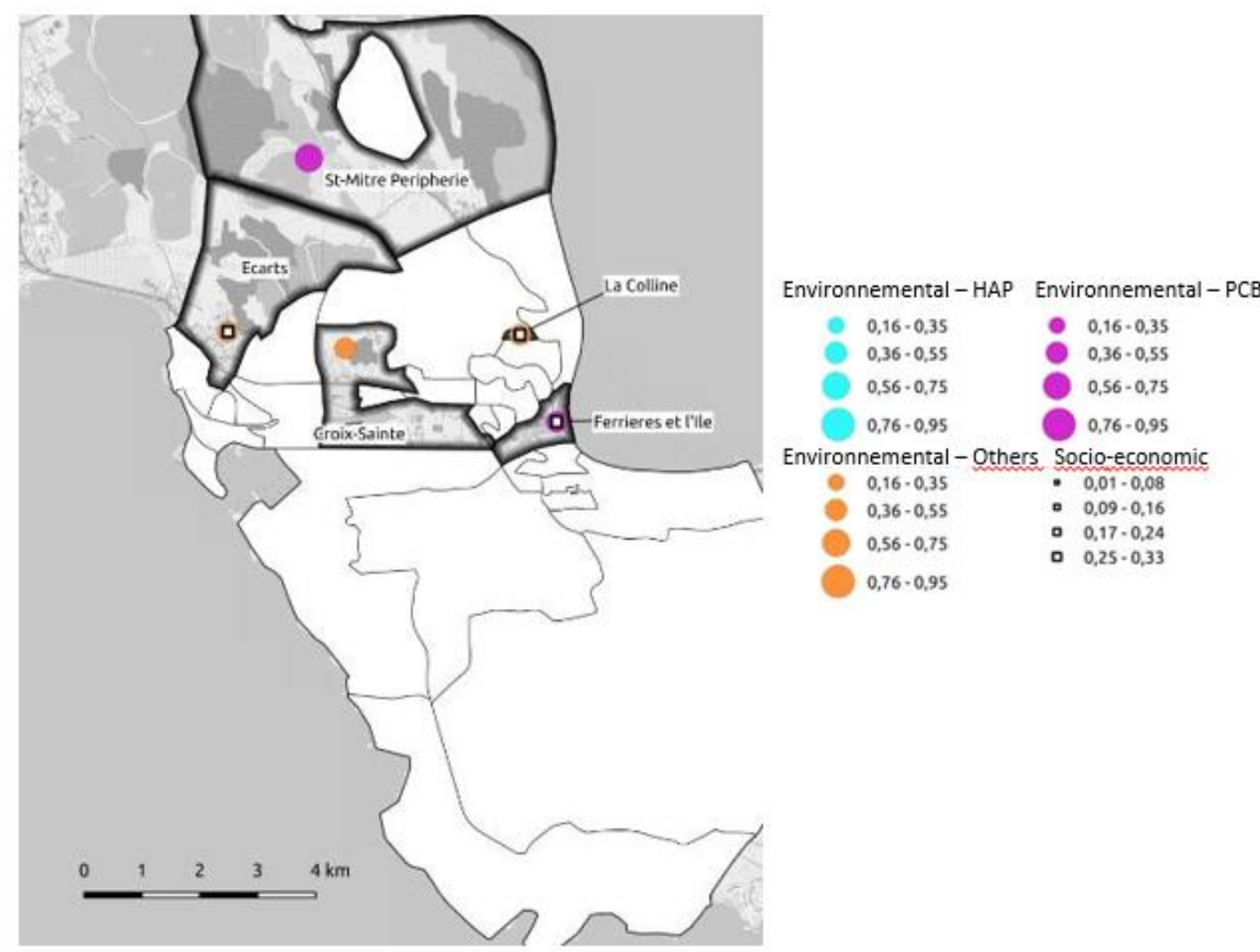

Profile of IRISes according to the probability of the prevalence of environmental and/or socio-economic factors Map No 5. Group 3 HCA, IRISes characterised by an increased prevalence of hospital stays related to cardiovascular diseases $(<15$ and $>65)$ and diabetes $(<15)$ 
Starting from this $4^{\text {th }}$ group, the number of stays is relatively lower; Canto Perdrix and Les Comtes Est stand out in regard to cardiovascular diseases in the over 65, with a prevalence of BkF_p for Canto Perdrix and a rather disadvantaged socioeconomy and a seemingly deleterious cocktail for Les Comtes Est (DCE, V_p, Hg and HF), since the impact is also observed on respiratory diseases in the over 65.

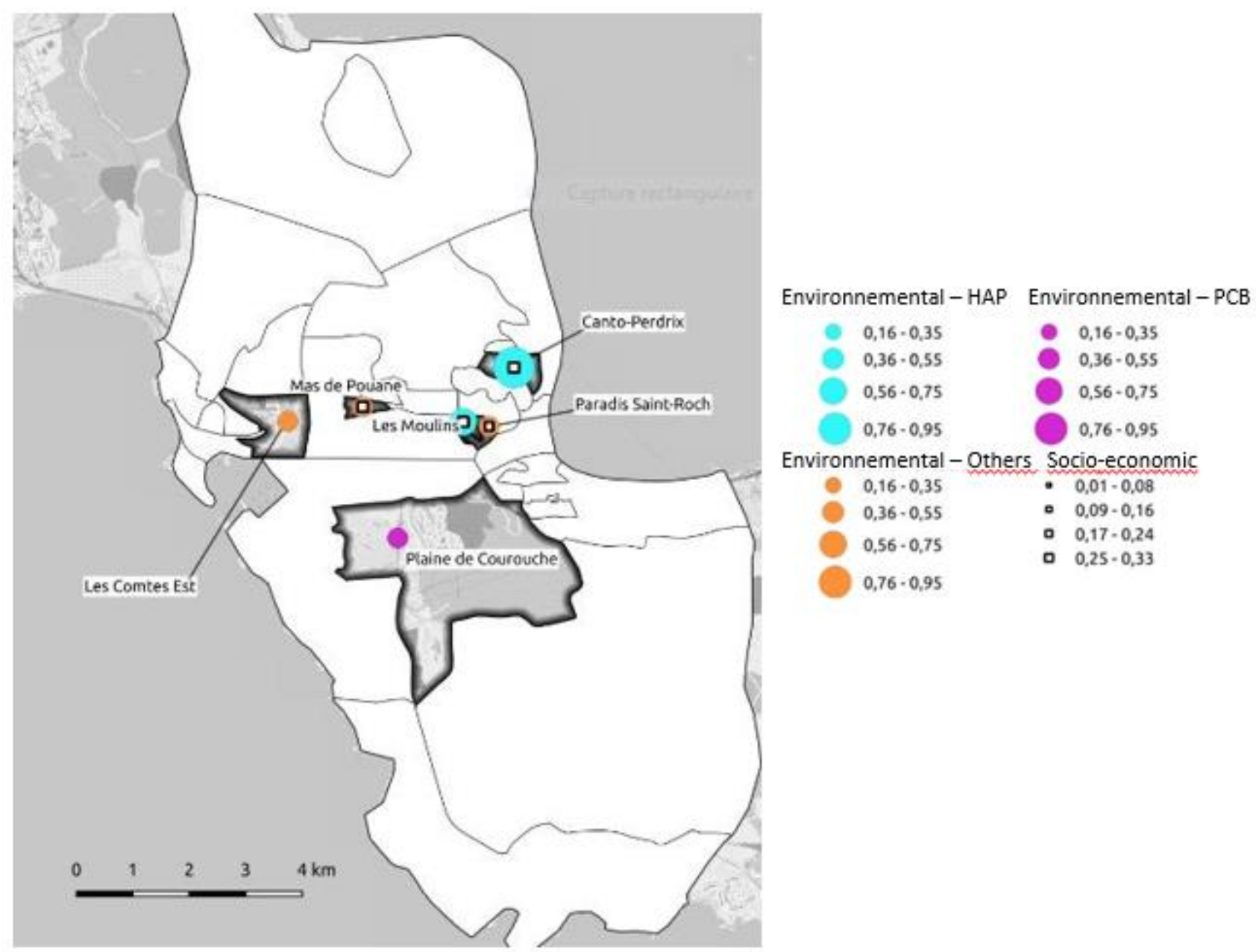

Profile of IRISes according to the probability of the prevalence of environmental and/or socio-economic factors Map No 6. Group 4 HCA, IRISes characterised by an increased prevalence of hospital stays related to cardiovascular diseases (>65) and respiratory diseases ( $<15$ and $>65)$ 
Finally, the control group is characterised by an overall number of pathologies lower than elsewhere, and above all less dangerous pollutants and/or in lower quantity than in the IRISes of the previous groups. Moreover, socio-economy being more favourable ${ }^{21}$, tends to offset their effects. This is particularly true for St-Mitre Centre. Nevertheless, it is "interesting" to note that the presence of $\mathrm{SO}_{2}$ alone has an influence on respiratory diseases in the 15-65 in the Figuerolles IRIS.

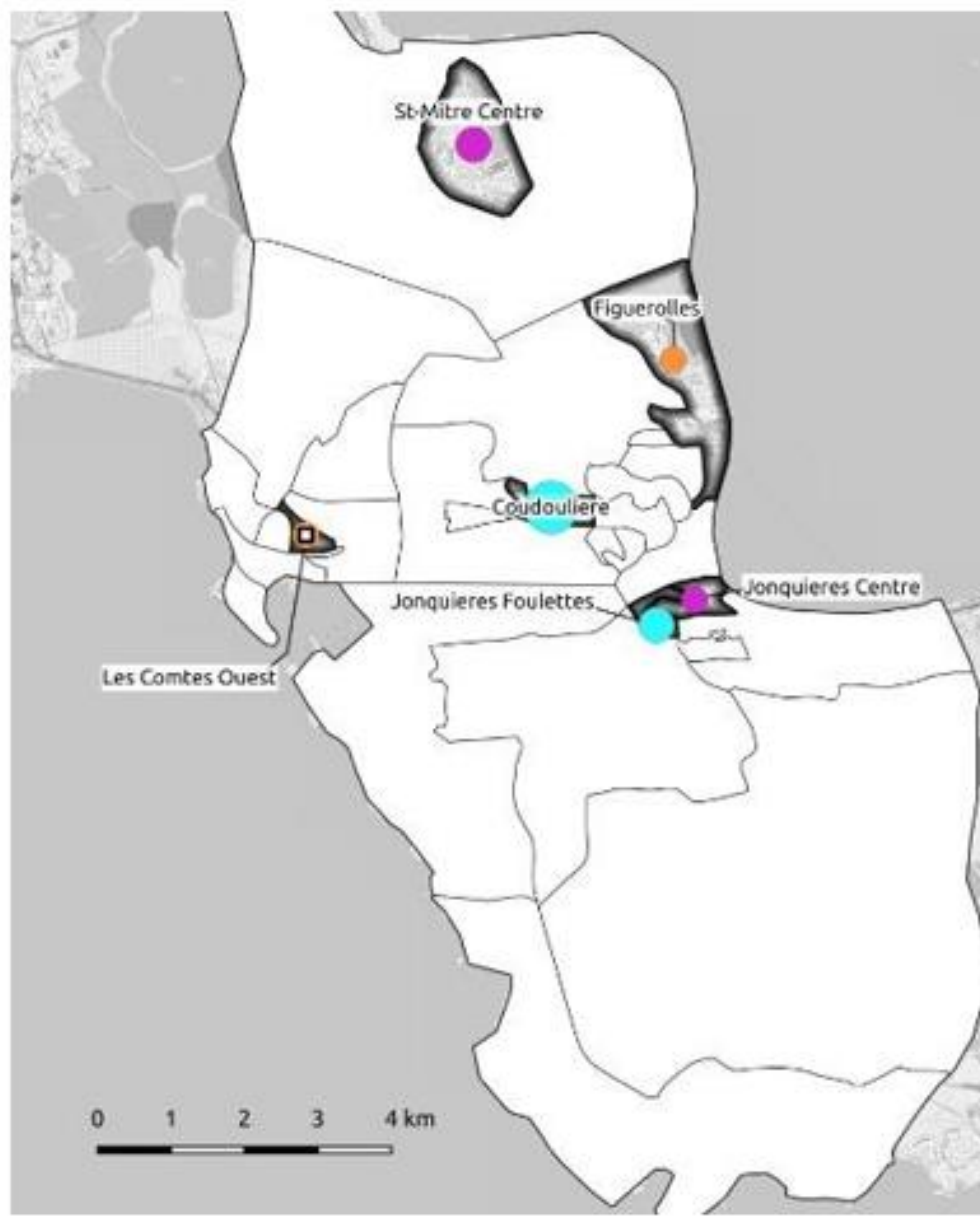

Environnemental-HAP Environnemental-PCB
e $0,16 \cdot 0,35$
$0,36 \cdot 0,55$ 0,36:0,55
$0,16-0,35$
$0,56 \cdot 0,75$
$0,56 \cdot 0,75$
$0,76 \cdot 0,95$
$0,76 \cdot 0,95$

Environnemental-Others Socio-economic

$0,16 \cdot 0,35$ - $0,01 \cdot 0,08$

$0,36 \cdot 0,55$ - $0,09-0,16$

$0,56 \cdot 0,75$ a $0,17 \cdot 0,24$

o $0,25 \cdot 0,33$

Profile of IRISes according to the probability of the prevalence of environmental and/or socio-economic factors Map No 7. Group 5 HCA, IRISes characterised by a lower prevalence of “Control group" pathologies

\footnotetext{
${ }^{21}$ Except in Comtes Ouest
} 
The summary map below depicts HAP emissions in the north-east part of the Pays de Martigues (Jonquières, Boudème), a vanadium and $\mathrm{SO}_{2}$ emission in Martigues' south neighbourhoods (Lavéra, Cote Bleue), and a PCB pollution over the entire territory. In the centre of the Pays de Martigues, disadvantaged socio-economy combines with the pollutants

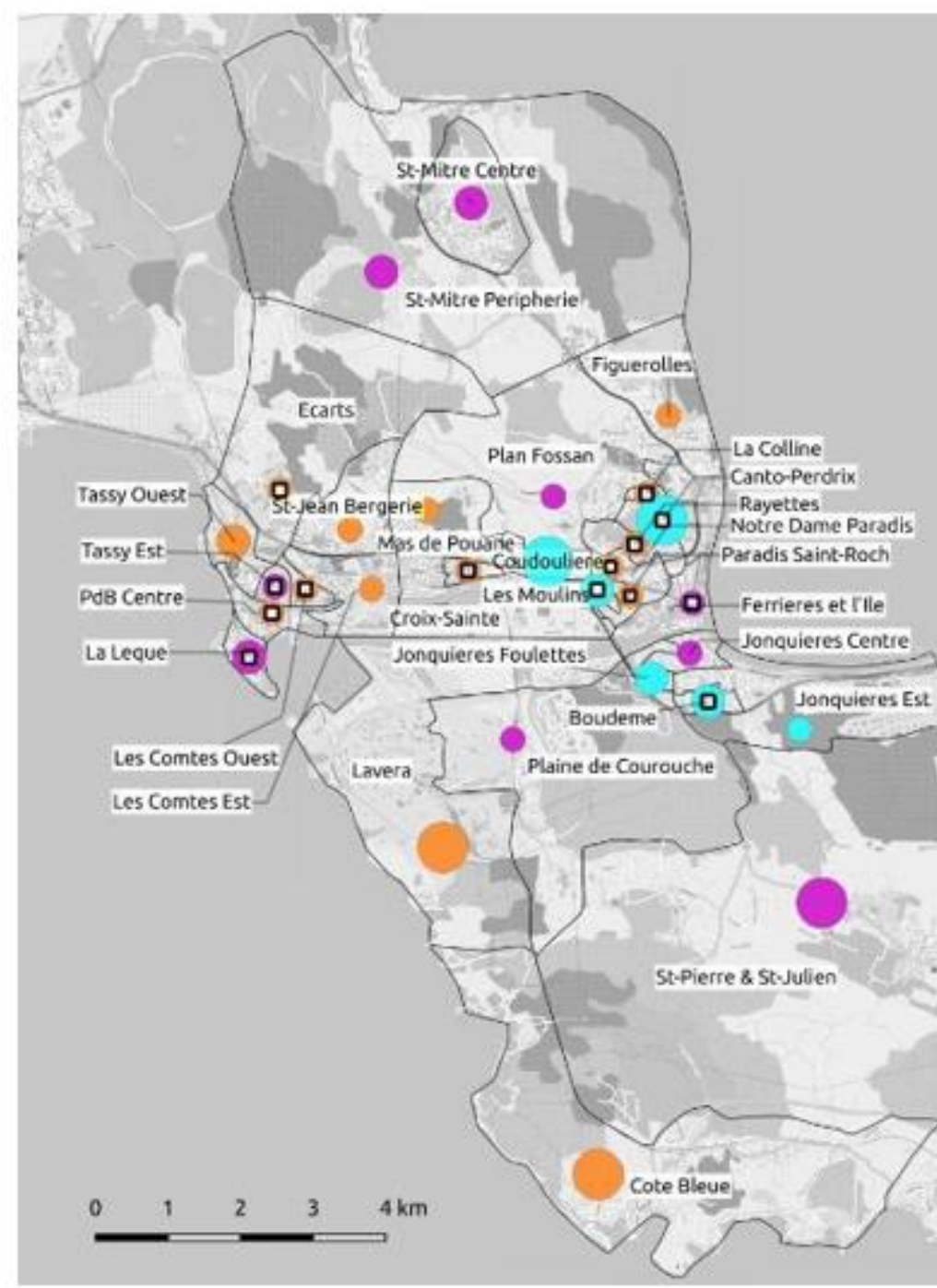

Environnemental-HAP Environnemental-PCB

$\begin{array}{ll}0,16 \cdot 0,35 & 0,16 \cdot 0,35 \\ 0,36 \cdot 0,55 & 0,36 \cdot 0,55 \\ 0,56 \cdot 0,75 & 0,56 \cdot 0,75 \\ 0,76 \cdot 0,95 & 0,76 \cdot 0,95\end{array}$

Environnemental-Others Socio-economic
$0,16 \cdot 0,35$
- $0,01-0,08$
$0,36 \cdot 0,55$
- $0,09 \cdot 0,16$
$0,56 \cdot 0,75$
- $0,17 \cdot 0,24$
- $0,25 \cdot 0,33$

$0,76 \cdot 0,95$

Profile of IRISes according to the prevalence of environmental and/or socio-economic factors

Map No 8. Summary map

\section{Discussion}

Like all studies, this one has its limits which we bring to your attention. First, the health data relate to numbers of hospital stays and not numbers of patients, because when this study was conducted, we could not access patient numbers. Therefore, an overestimate of cases is possible, because some pathologies may have necessitated several hospital stays to be treated (this is particularly true concerning bladder cancers). Likewise, as we are working at a fine scale, the number of cases for some pathologies and in some IRISes can sometimes be low and induce biases. However, because Bayesian networks work, in a way, by comparing the evolution of proportion between variables, the risk of bias is minimised. The fact of having chosen annual averages for atmospheric pollutants rather than deciles tends to smooth out the effects of atmospheric pollutants. Pollutant data, like health data, are those of 2015, but we know that in the case of cancers there is a time gap that can be long between the exposure and its effect, but this seems to be less so for respiratory and cardiovascular diseases and diabetes. Finally, we only took into account residential exposure, and not professional or related to daily commuting. Finally, although the lichen plots are 
scattered over the entire study territory and located according to the IRISes' socioeconomic level, had we had more of them would have enabled us to ascertain our results even better. Studies carried out on environmental health are most of the time criticised because of the difficulty to get to the root causes of pathologies. Another frequently heard argument is the multifactorial character of an individual's health. Furthermore, the design of these studies is most of the time of the ecological kind and can also lead to attribute to individuals the effect of pollutants measured in a space (ecological fallacy), but this argument is itself put into question. [42]

Nonetheless, by taking into account the highest possible number of variables in terms of pollutants and socio-economy which can potentially influence the health of residents, and doing so at a fine scale (the nearest to that of the majority of individuals living in urban areas), on the base of proven pathologies, and using an appropriate mathematical formalism, based on conditional probabilities, we can then presuppose a certain number of causal factors.

Thus, we have been able to bring forward several relations between exposure to xenobiotics and proven pathologies, sufficient enough to have required an hospital stay in 2015, and which suggest the recommendations below.

Among the relations found, efforts must focus on reducing $\mathrm{SO}_{2}$ emissions, having observed that it has an impact from a very low threshold, far below standards. Companies must continue and ramp up the desulphurisation process of their installations, or, when possible, use a lower-sulphur fuel. However, $\mathrm{SO}_{2}$ exposure is not only due to companies operating in the territory, the annual volume of tankers bringing their load to the Fos-sur-Mer Industrial Port zone also plays a part. There again, resorting to a lower-sulphur fuel could contribute to improving the health of residents. It appears that in this territory there is diffuse PCB pollution, linked to respiratory diseases in the over 65 , which should be investigated more closely in order to take appropriate measures quickly (site remediation by phytomanagement) [43, 44].

Several thresholds have appeared, above which certain pollutants were particularly noxious, and in that sense, the Bayesian model will have contributed to revealing them, as is the case, for example, with hydrofluoric acid (HF), the effect of which already appeared at the $0.0028 \mu \mathrm{g} / \mathrm{m}^{3}$ threshold, whereas exposure to cadmium in its particle phase, for an exposure between 0.214 and $0.250 \mu \mathrm{g} / \mathrm{m}^{3}$, disrupts insulin metabolism in the over 65 . Finally, as soon as benzo[k]fluoranthene (particle phase) exceeds the $0.672 \mu \mathrm{g} / \mathrm{m}^{3}$ threshold, it is reflected by a higher number of hospital stays for respiratory diseases in the 15-65.

The role of specific pollutants in the profile category such as chrome, chrome $\mathrm{VI}$ and vanadium in their particle phase, deserves appropriate monitoring. Therefore, emissions of these pollutants should be reduced, when it is technically and financially possible, below such thresholds (substitute products, less polluting industrial processes, more effective filters).

\section{Conclusions}

The study has revealed differentiated health profiles between the various IRISes which constitute the Pays de Martigues territory, which should lead to supplying health care that would be better suited to the needs of the population, from a prevention perspective, and even to promote consultations with certain specialists. For example, with a cardiologist, in those IRISes where the number of unqualified 15-year olds is significant, since a relation has been found at that level, a relation most probably due to more difficult living or working conditions for these people.

Likewise, prevention and social support measures should be taken to the benefit of single-parent families. As for companies in the study area, they should continue to reduce their emissions concerning the noxious pollutants found. Lastly, present-day pathologies are most of the time the result of former exposures when pollution levels were overall higher. Il would be interesting to obtain older measurements concerning the incriminated pollutants and redo the calculations. 


\section{Declarations}

\section{Availability of data and materials}

The datasets used and/or analyzed during the current study are available from the corresponding author on reasonable request, excepting the health data, because the French national commission for Informatics and Freedoms (CNIL) does not allow their sharing.

\section{List of abbreviations}

CB169: PCB 169 3,3',4,4',5,5'-Hexachlorobiphenyl

R: Correlation coefficient

BkF_p: Benzo[k]fluoranthene particle phase (a letter $p$ after a pollutant indicates that it is this pollutant's particle phase, and not its gaseous phase)

HF: Hydrofluoric acid

Cd_p: Cadmium particle phase

$\mathrm{HCl}$ : Hydrochloric acid

IRIS: Block groups for Statistical Information, INSEE infra-communal breakdown

P14_PMEN_ANEM10P: number of people in households living in the IRIS in 2014 for over 10 years

P14_NSCOL15P_DIPLO: number of unschooled people aged 15 or over and without qualification

C14_PMEN_MENFAMMONO: number of people in households whose main family is a single-parent family

P14_NPER_RP_LOC: number of people in main homes occupied by tenants

P14_POP_IMM1: number of immigrants

P14_CHOM15642: number of unemployed aged 15 to 64

DEC_MED14: median income

HAP: Polycyclic aromatic Hydrocarbons

I00I9915ans: all cardiovascular diseases in the under 15

I00I991565ans: all cardiovascular diseases in the 15-65

I00I9965ans: all cardiovascular diseases in the over 65

J00J9915ans: all respiratory diseases in the under 15

J00J991565ans: all respiratory diseases in the 15-65

J00J9965ans: all respiratory diseases in the over 65

E10E1415ans: all diabetes types (I \& II) in the under 15

E10E1465ans: all diabetes types (I \& II) in the 15-65

E10E1465ans: all diabetes types (I \& II) in the over 65

C3415ans: all types of bronchus and lung cancer in the under 15

C341565ans: all types of bronchus and lung cancer in the 15-65

C3465ans: all types of bronchus and lung cancer in the over 65

C6715ans: all types of bladder cancer in the under 15

C671565ans: all types of bladder cancer in the 15-65

C6765ans: all types of bladder cancer in the over 65

C6415ans: all types of kidney cancer in the under 15

C641565ans: all types of kidney cancer in the 15-65

C6465ans all types of kidney cancer in the over 65

PCB: Polychlorobiphenyls

PCDDF: Dioxins and Furans

Cr_p: Chromium in particle phase

Cr6_p: Chromium VI, hexavalent Chromium

CB194: 2,2',3,3',4,4',5,5'-Octachlorobiphenyl

CO: Carbon monoxide

CB187: 2,2',3,4',5,5',6-Heptachlorobiphenyl

TEQ 2005: sum of PCBs and dioxins/furans in toxic equivalents such as defined by the WHO in 2005

2,3,7,8 TeCDF: 2,3,7,8-Tetrachlorodibenzofuran

2,3,4,7,8 PeCDF: 2,3,4,7,8-Pentachlorodibenzofuran

As: Arsenic

S02: Sulphur dioxide 
VDL: Lichen diversity value

CB20: 2,3,3'-Trichlorobiphenyl

CB114: 2,3,4,4',5-Pentachlorobiphenyl

CB157: 2,3,3',4,4',5'-Hexachlorobiphenyl

PM10 diesel: Under $10 \mu \mathrm{m}$ diameter particles

PM2,5 diesel: Under $2.5 \mu \mathrm{m}$ diameter particles

IcdP: Indeno [1,2,3 c, d] pyrene

BbF: Benzo[b]fluoranthene

BaP: Benzo[a]pyrene

BaA: Benzo[a]anthracene

Daha: Dibenzo [a,h]anthracene

Cu: Copper

Benz: Benzene

NO2: Nitrogen dioxide

CB180: 2,2',3,4,4',5,5'-Heptachlorobiphenyl

$\mathrm{Ni}$ : Nickel

Zn: Zinc

Se or Sn: Selenium

$\mathrm{Pb}$ : Lead

CB170: 2,2',3,3',4,4',5-Heptachlorobiphenyl

$\mathrm{V}$ : Vanadium

CB169: 3,3',4,4',5,5'-Hexachlorobiphenyl

CB194: 2,2',3,3',4,4',5,5'-Octachlorobiphenyl

CB187: 2,2',3,4',5,5',6-Heptachlorobiphenyl

Bpe: Benzo(ghi)perylene

CB195: 2,2',3,3',4,4',5,6-Octachlorobiphenyl

CB153: 2,2',4,4',5,5'-Hexachlorobiphenyl

1,2,3,4,6,7,8 HpCDF: 1,2,3,4,6,7,8-Heptachlorodibenzofuran 1,2,3,4,6,7,8,9 OCDF: 1,2,3,4,6,7,8,9-Octachlorodibenzofuran CB149: 2,2',3,4',5',6-Hexachlorobiphenyl

CB123: 2,3',4,4',5'-Pentachlorobiphenyl

CB28: 2,4,4'-Tri chlorobiphenyl

CB44: 2,2',3,5'-Tetrachlorobiphenyl

IPA: Atmospheric Purity Index

1,2,3,4,6,7,8,9 OCDD: 1,2,3,4,6,7,8,9-Octachlorodibenzodioxin

CB77: 3,3',4,4'-Tetrachlorobiphenyl

CB126: 3,3',4,4',5-Pentachlorobiphenyl

CB153: 2,2',4,4',5,5'-Hexachlorobiphenyl

CB138: 2,2',3,4,4', $5^{\prime}$-Hexachlorobiphenyl

CB128: 2,2',3,3',4,4'-Hexachlorobiphenyl

CB101: 2,2',4,5,5'-Pentachlorobiphenyl

DCE: Dichloroethane

CB105: 2,3,3',4,4'-Pentachlorobiphenyl

1,2,3,6,7,8 HeCDF: Hexachlorodibenzo-p-furan

Fe: Iron

CB18: 2,2',5-Trichlorobiphenyl

CB151: 2,2',3,5,5',6-Hexachlorobiphenyl

CB156: 2,3,3',4,4',5-Hexachlorobiphenyl

FIA: Fluoranthene

Ace: Acenaphthene

Acy: Acenaphthylene

Ant: Anthracene

CB31: 2,4',5-Trichlorobiphenyl

Nap: Naphthalene

CB141: 2,2',3,4,5,5'-Hexachlorobiphenyl

Ipy: Indeno(1,2,3-cd)pyrene

Phe: Phenanthrene 
Flu: Fluorene

CB52: 2,2',5,5'-Tetrachlorobiphenyl

CB183: 2,2',3,4,4',5',6-Heptachlorobiphenyl

CB196: 2,2',3,3',4,4',5,6'-Octachlorobiphényle

CB201: 2,2',3,3',4,5',6,6'-Octachlorobiphenyl

CB95: 2,2',3,5',6-Pentachlorobiphényle

CB118: 2,3',4,4',5-Pentachlorobiphenyl

CB87: 2,2',3,4,5'-Pentachlorobiphenyl

CB92: 2,2',3,5,5'-Pentachlorobiphenyl

$\mathrm{Hg}$ : Mercury

1,2,4,7,8 HeCDF: Tetrachlorodibenzo-p-furan

1,2,3,7,8 HeCDD: 2,3,7,8-Tetrachlorodibenzo-p-dioxin

1,2,3,6,7,8 HeCDD: 1,2,3,6,7,8-Hexachlorodibenzo-p-dioxin

1,2,3,4,6,7,8 HpCDD: 1,2,3,4,6,7,8-Heptachlorodibenzo-P-dioxin

CB60: 2,3,4,4'-Tetrachlorobiphenyl

CB151: 2,2',3,5,5',6-Hexachlorobiphenyl

CB174: 2,2',3,3',4,5,6'-Heptachlorobiphenyl

CB81: 3,4,4',5-Tetrachlorobiphenyl

CB136: 2,2',3,3',6,6'-Hexachlorobiphenyl

\section{References}

1. Mantey K, Pascal L, Cortaredona S. Observatoire des cancers du rein, de la vessie et des leucémies aiguës chez l'adulte dans le département des Bouches-du-Rhône (REVELA13). Analyses spatiales, 2013-2016. SaintMaurice : Santé publique France, 2019. 80 p. https://www.santepubliquefrance.fr/regions/provence-alpescote-d-azur-et-corse/documents/rapport-synthese/2019/observatoire-des-cancers-du-rein-de-la-vessie-etdes-leucemies-aigues-chez-l-adulte-dans-le-departement-des-bouches-du-rhone-revela13-analyses

2. Allen B, Cohen A, Ferrier Y, Lees J, 2017. Fos EPSEAL, Étude participative en santé environnement ancrée localement sur le front industriel de Fos-sur-Mer et Port-Saint-Louis-du-Rhône, Rapport final, Marseille : Centre Norbert Elias

3. Jeanjean $\mathrm{M}$, Lees J, Allen BL, Cohen A. Interdisciplinary community-based participatory health research across the industrial region of the Étang de Berre: The EPSEAL Fos Crau study. Revue d'Épidémiologie et de Santé Publique 2021:S0398762021003254. https://doi.org/10.1016/i.respe.2021.04.141.

4. Fortin M, Haggerty J, Sanche S, Almirall J. Self-reported versus health administrative data: implications for assessing chronic illness burden in populations. A cross-sectional study. CMAJ Open 2017;5:E729-33. https://doi.org/10.9778/cmajo.20170029.

5. Goix S, Periot M, Douib K. Etude INDEX. Etude d'imprégnation de la population aux polluants atmosphériques de la zone industrialo-portuaire de Fos-sur-Mer. Institut Ecocitoyen pour la Connaissance des Pollutions (IECP) 2018, 296p.https://www.institut-ecocitoyen.fr/publication/1/SANTE\%20-\%202018\%20\%20INDEX\%20[Rapport\%20etude\%20Goix].pdf

6. AtmoSud, Etude SCENARII : Simulation de scénarii de pollution atmosphérique pour une Evaluation des Risques Sanitaires - Zone Etang de Berre

7. AtmoSud, Etude Polis : Plan d'Observation des Polluants d'Intérêt Sanitaire, 2016

8. Pérez S, 2016, Etude de faisabilité sur le croisement des informations disponibles sur les zones à risques potentiels et le recensement de pathologies avérées et géo-localisées à l'échelle du territoire du Pays de Martigues, $35 \mathrm{p}$.

9. Park J, Kim H-J, Lee C-H, Lee CH, Lee HW. Impact of long-term exposure to ambient air pollution on the incidence of chronic obstructive pulmonary disease: A systematic review and meta-analysis. Environmental Research 2021; 194: 110703. https://doi.org/10.1016/i.envres.2020.110703.

10. Adam M, Schikowski T, Carsin AE, Cai Y, Jacquemin B, Sanchez M, et al. Adult lung function and long-term air pollution exposure. ESCAPE: a multicentre cohort study and meta-analysis. Eur Respir J 2015;45:38-50. https://doi.org/10.1183/09031936.00130014.

11. Atkinson RW, Carey IM, Kent AJ, van Staa TP, Anderson HR, Cook DG. Long-term exposure to outdoor air pollution and the incidence of chronic obstructive pulmonary disease in a national English cohort. Occup Environ Med 2015; 72:42-8. https://doi.org/10.1136/oemed-2014-102266. 
12. Khaniabadi YO, Polosa R, Chuturkova RZ, Daryanoosh M, Goudarzi G, Borgini A, et al. Human health risk assessment due to ambient PM10 and SO2 by an air quality modeling technique. Process Safety and Environmental Protection 2017; 111: 346-54. https://doi.org/10.1016/i.psep.2017.07.018

13. Doiron D, de Hoogh K, Probst-Hensch N, Fortier I, Cai Y, De Matteis S, et al. Air pollution, lung function and COPD: results from the population-based UK Biobank study. Eur Respir J 2019;54:1802140. https://doi.org/10.1183/13993003.02140-2018.

14. Guo C, Zhang Z, Lau A.K.H, Lin C.Q, Chuang, Y.C, Chan, J, et al., 2018. Effect of long-term exposure to fine particulate matter on lung function decline and risk of chronic obstructive pulmonary disease in Taiwan: a longitudinal, cohort study. The Lancet Planetary Health 2, e114-e125.

15. Cai Y, Zhang B, Ke W, Feng B, Lin H, Xiao J, et al. Associations of Short-Term and Long-Term Exposure to Ambient Air Pollutants With Hypertension: A Systematic Review and Meta-Analysis. Hypertension 2016;68:62-70. https://doi.org/10.1161/HYPERTENSIONAHA.116.07218.

16. Münzel T, Sørensen M, Gori T, Schmidt FP, Rao X, Brook FR, et al. Environmental stressors and cardio-metabolic disease: part II-mechanistic insights. Eur Heart J 2016: ehw294. https://doi.org/10.1093/eurheartj/ehw294.

17. Suissa L, Fortier M, Lachaud S, Staccini P, Mahagne M-H. Ozone air pollution and ischaemic stroke occurrence: a case-crossover study in Nice, France. BMJ Open 2013; 3: e004060. https://doi.org/10.1136/bmjopen-2013$\underline{004060 .}$

18. Hwang J, Kwon J, Yi H, Bae H-J, Jang M, Kim N. Association between long-term exposure to air pollutants and cardiopulmonary mortality rates in South Korea. BMC Public Health 2020;20:1402. https://doi.org/10.1186/s12889-020-09521-8.

19. Mazenq J, Dubus J-C, Gaudart J, Charpin D, Nougairede A, Viudes G, et al. Air pollution and children's asthmarelated emergency hospital visits in southeastern France. Eur J Pediatr 2017;176:705-11. https://doi.org/10.1007/s00431-017-2900-5

20. Yang B-Y, Fan S, Thiering E, Seissler J, Nowak D, Dong G-H, et al. Ambient air pollution and diabetes: A systematic review and meta-analysis. Environmental Research 2020;180:108817. https://doi.org/10.1016/j.envres.2019.108817.

21. Castano-Vinyals G, Cantor KP, Malats N, Tardon A, Garcia-Closas R, Serra C, et al. Air pollution and risk of urinary bladder cancer in a case-control study in Spain. Occupational and Environmental Medicine 2008;65:56-60. https://doi.org/10.1136/oem.2007.034348.

22. Ratier A, Dron J, Revenko G, Austruy A, Dauphin C-E, Chaspoul F, et al. Characterization of atmospheric emission sources in lichen from metal and organic contaminant patterns. Environ Sci Pollut Res 2018;25:8364-76. https://doi.org/10.1007/s11356-017-1173-x.

23. Conrady S, Jouffe L. Bayesian Networks and BayesiaLab: A Practical Introduction for Researchers. 2015.

24. Pearl J. Causal inference in statistics: An overview. Statist Surv 2009;3. https://doi.org/10.1214/09-SS057.

25. Pearl J. Probabilistic Reasoning in Intelligent Systems: Networks of Plausible Inference. 2014.

26. Pearl J. Causality: Models, Reasoning, and Inference. 2nd ed. Cambridge: Cambridge University Press; 2009. https://doi.org/10.1017/CBO9780511803161.

27. Pearl J, Mackenzie D. The book of why: the new science of cause and effect. First edition. New York: Basic Books; 2018.

28. Sottas P-E, Lavoué J, Bruzzi R, Vernez D, Charrière N, Droz P-O. An empirical hierarchical Bayesian unification of occupational exposure assessment methods. Statist Med 2009; 28:75-93. https://doi.org/10.1002/sim.3411.

29. Weber P, Simon C. Benefits of Bayesian network models. London, UK: Hoboken, NJ, USA: ISTE; Wiley; 2016.

30. Carter P, Lagan J, Fortune C, Bhatt DL, Vestbo J, Niven R, et al. Association of Cardiovascular Disease with Respiratory Disease. Journal of the American College of Cardiology 2019;73:2166-77. https://doi.org/10.1016/i.jacc.2018.11.063.

31. Van den Berg M, Birnbaum LS, Denison M, De Vito M, Farland W, Feeley M, et al. The 2005 World Health Organization Reevaluation of Human and Mammalian Toxic Equivalency Factors for Dioxins and Dioxin-Like Compounds. Toxicological Sciences 2006;93:223-41. https://doi.org/10.1093/toxsci/kfl055.

32. Buha A, Đukić-Ćosić $D$, Ćurčić $M$, Bulat Z, Antonijević B, Moulis J-M, et al. Emerging Links between Cadmium Exposure and Insulin Resistance: Human, Animal, and Cell Study Data. Toxics 2020;8:63. https://doi.org/10.3390/toxics8030063.

33. Schwartz, G. II'Yasova, D, Ivanova, A. Urinary cadmium, impaired fasting glucose, and diabetes in the NHANES III. Diabetes Care 2003, 26, 468-470.

34. Picheral, H. Complexes et systèmes pathogènes : approche géographique ?, De l'épidémiologie à la géographie humaine. Travaux et documents de géographie tropicale, 1983, nº 48, p. 5-22. 
35. Evangelou E, Ntritsos G, Chondrogiorgi M, Kavvoura FK, Hernández AF, Ntzani EE, et al. Exposure to pesticides and diabetes: A systematic review and meta-analysis. Environment International 2016;91:60-8. https://doi.org/10.1016/i.envint.2016.02.013

36. Mendes V, Ribeiro C, Delgado I, Peleteiro B, Aggerbeck M, Distel E, et al. The association between environmental exposures to chlordanes, adiposity and diabetes-related features: a systematic review and meta-analysis. Sci Rep 2021;11:14546. https://doi.org/10.1038/s41598-021-93868-4.

37. Svingen T, Vinggaard AM. The risk of chemical cocktail effects and how to deal with the issue. J Epidemiol Community Health 2016;70:322-3. https://doi.org/10.1136/jech-2015-206268.

38. Sarigiannis DA, Hansen U. Considering the cumulative risk of mixtures of chemicals - A challenge for policy makers. Environ Health 2012;11: S18. https://doi.org/10.1186/1476-069X-11-S1-S18.

39. Lees REM. Changes in lung function after exposure to vanadium compounds in fuel oil ash. Occupational and Environmental Medicine 1980; 37:253-6. https://doi.org/10.1136/oem.37.3.253.

40. Agency for Toxic Substances and Disease Registry (ATSDR). 2012. Toxicological Profile for Vanadium. Atlanta, GA: Department of Health and Human Services, Public Health Service

41. Grandjean P. Paracelsus Revisited: The Dose Concept in a Complex World. Basic Clin Pharmacol Toxicol 2016;119:126-32. https://doi.org/10.1111/bcpt.12622.

42. Schwartz S. The fallacy of the ecological fallacy: the potential misuse of a concept and the consequences. Am J Public Health 1994;84:819-24. https://doi.org/10.2105/AJPH.84.5.819.

43. Aken BV, Correa PA, Schnoor JL. Phytoremediation of Polychlorinated Biphenyls: New Trends and Promises. Environ Sci Technol 2010;44:2767-76. https://doi.org/10.1021/es902514d.

44. Passatore L, Rossetti S, Juwarkar AA, Massacci A. Phytoremediation and bioremediation of polychlorinated biphenyls (PCBs): State of knowledge and research perspectives. Journal of Hazardous Materials 2014;278:189202. https://doi.org/10.1016/j.jhazmat.2014.05.051.

\section{Acknowledgements}

The authors wish to thank all those with whom they have been in touch in the course of this study, and more particularly the Conseil de Territoire du Pays de Martigues within the Métropole Aix-Marseille-Provence, and the CIAS of Pays de Martigues for their trust and support.

\section{Funding}

The feasibility study has been financed by ARS PACA within the framework of the AAP PRSE 2015, and the study itself by the Conseil de Territoire du Pays de Martigues within the Métropole Aix-Marseille-Provence, and the Pays de Martigues Centre Intercommunal d'Action Sociale (CIAS).

\section{Author information}

\section{Affiliation}

University Cote d'Azur, UMR 7300 ESPACE, France

Sandra Pérez

Centre intercommunal de l'action sociale du Pays de Martigues

Catherine German Labaume

Association agrée pour la surveillance de la qualité de l'air en région Sud, Atmosud

Sébastien Mathiot

Institut Ecocitoyen pour la connaissance des pollutions

Sylvaine Goix

Philippe Chamaret 


\section{Contributions}

Project conceptualizing, design of the study, data analysis, writing: SP, Project administration, Funding acquisition, Literature review: GL, Manuscript preparation: SP, SG, Visualization: SG, Participation in the data collection and provided technical input to the data analyses: SM, PC, Validation: SM. All authors read and approved the final manuscript.

\section{Corresponding author}

Correspondence to Sandra Pérez.

\section{Ethics declarations}

\section{Consent for publication}

This manuscript does not contain any individual person's data in any form.

\section{Competing interests}

The authors declare that they have no competing interests.

Figures, tables and additional files 